\title{
Monetary Policy and Inequality: How Does One Affect the Other?*
}

\author{
Job Market Paper
}

\author{
Eunseong $\mathrm{Ma}^{\dagger}$ \\ Texas A\&M University
}

November 5, 2018

\begin{abstract}
This study investigates the relation between monetary policy and inequality by asking how one affects the other: the effect of monetary policy on inequality and the impact of the long-run level of inequality on the effectiveness of monetary policy. To this end, I incorporate nominal wage contracts and cash-in-advance constraints into a heterogeneous agent model economy with indivisible labor. I find that expansionary monetary policy reduces income, wealth, and consumption inequalities mainly due to a rise in employment from the bottom of the distributions. There are heterogeneous effects on income across the wealth distribution: in response to an unanticipated monetary easing, households in the bottom of the wealth distribution benefit from an increase in employment while rich households benefit from a rise in the real asset returns in a relative sense. An unexpected monetary expansion also has asymmetric responses of consumption between the poor and the rich: asset-poor households increase their consumption while it falls for wealthy households. This implies that inflation hurts the rich more. I also find that the long-run prevailing levels of inequality matter for the effectiveness of monetary policy by determining the size of labor supply elasticity, which represents the shape of reservation wage distribution. All else being equal, a more equal economy is associated with more effective monetary policy in terms of output. I also provide empirical evidence for this model result using state-level panel data: the effects of monetary policy shocks on output are larger for lowinequality states.
\end{abstract}

JEL classification: D31; D52; E52

Keywords: Monetary policy; Inequality; Nominal wage rigidity; Indivisible labor; Cash-in-advance constraint

*I am deeply indebted to Sarah Zubairy for her continuous advice and guidance. I would like to thank my dissertation committee members, Dennis Jansen, Hwagyun (Hagen) Kim, and Yuzhe Zhang for their helpful discussion and support. I am also grateful to Dunpei Gan, ShinHyuck Kang, Daisoon Kim, Kwangyong Park, Tatevik Sekhposyan, Kei-Mu Yi, Minchul Yum, and seminar or conference participants at Texas A\&M University, 2018 Fall Midwest Macro Meetings, and 71st European Meeting of the Econometric Society for their valuable comments and suggestions.

†Department of Economics, Texas A\&M University, College Station, TX 77843, Email: masilver85@tamu.edu. 


\section{Introduction}

The unequal distributions of income and wealth have become a primary concern for economists and policy makers (Piketty, 2014; White House, 2017). In recent years, such inequality is particularly relevant for the stabilization role of economic policies since policies might have disparate effects across different segments of the population. This study investigates the relation between monetary policy and inequality. On the one hand, discretionary changes in monetary policy actions can have distributional effects on consumption, income, and wealth in the short run. ${ }^{1}$ On the other hand, the level of inequality may affect the effectiveness of monetary policy in the long run. ${ }^{2}$ Specifically, this paper studies both the effects of monetary policy on inequality and the role of the long-run level of inequality in the effectiveness of monetary policy, by answering the following questions:

1. How does discretionary monetary policy affect income, consumption and wealth inequality, and what is the key mechanism?

2. How does the long-run level of inequality affect the effectiveness of monetary policy in terms of output, and what is the linkage?

In regards to the first question, an increasing concern about economic inequality has resulted in monetary policymakers discussing the potential distributional effects of monetary policy instruments (Mersch, 2014; Bullard, 2014; Bernanke, 2015). However, how monetary policy actions affect inequality is still ambiguous since there are a number of underlying channels as pointed out by Mersch (2014) and Bernanke (2015). ${ }^{3}$ In this paper, I propose a new transmission mechanism of the distributional effects of monetary policy by developing a heterogeneous agent model economy with nominal wage contracts and indivisible labor. ${ }^{4}$ In this model economy, nominal wage contracts are important for explaining the

\footnotetext{
${ }^{1}$ In this paper, I do not focus on the effect of systematic parts of monetary policy.

${ }^{2}$ The "effectiveness of monetary policy" is defined as the extent to which monetary policy affects output, i.e., the responsiveness of output.

${ }^{3}$ Coibion et al. (2017) discuss the possible channels of the distributional effects of monetary policy: portfolio channel (households hold different financial assets), the savings redistribution channel (savers and borrowers are differentially affected by monetary policy), the financial segmentation channel (households have different access to financial markets and instruments). Auclert (2017) focuses on the three channels: an earnings heterogeneity channel from unequal income gains, Fisher channel from unexpected inflation, and interest rate exposure channel from real interest rate changes.

${ }^{4}$ Some recent studies in the literature provide channels of redistributive effects of monetary policy in the context of New Keynesian frameworks. For example, Kaplan, Moll and Violante (2018) focus on the role of the different marginal propensities to consume (MPC) across households by incorporating both liquid and illiquid assets, and Gornemann, Kuester
} 
disaggregate effects of monetary policy shocks. As far as the second question is concerned, how the long-run level of economic inequality affects the effectiveness of monetary policy is also an important issue, when considering different degrees of inequality across countries and even within a country. In spite of its importance, this topic is relatively unstudied in the literature, and existing papers (e.g., Kim (2017) and Cravino, Lan and Levchenko (2018)) do not have a general consensus. ${ }^{5}$ Filling this gap is another primary goal of this study.

To study the relation between monetary policy and inequality, I build a dynamic stochastic general equilibrium (DSGE) model where there is a large population of heterogeneous households, a government, and many identical firms. In the model economy, it is assumed that asset markets are incomplete as in Huggett (1993) and Aiyagari (1994) in that households cannot fully insure against their idiosyncratic productivity shocks. Cash-in-advance constraints are considered in the standard real business cycle model as in Cooley and Hansen (1989). ${ }^{6}$ Importantly, nominal wage contracts are also introduced in the model economy as in Cho and Cooley (1995) and Janko (2008). Nominal wage contracts play an important role in a monetary transmission mechanism for both aggregate and disaggregate effects. Due to the nominal wage contracts, real wages will reasonably respond to money supply changes. This will allow firms to change labor demand and affect employment, income, and consumption decisions of households. Therefore, under the nominal wage contract, labor market dynamics is more important in the transmission mechanism of monetary policy actions rather than intertemporal substitution effects. Following Hansen (1985), Rogerson (1988) and Chang and Kim (2007), it is assumed that a household indivisibly decides hours of work. ${ }^{7}$ The indivisible labor supply assumption in the heterogeneous-agent model can endogenously generate aggregate labor supply curves. The degree of heterogeneity in the economy matters for the shape of reservation wage distributions, thereby affecting and Nakajima (2016) build an incomplete asset market model where matching frictions create countercyclical labor-market risks.

${ }^{5} \mathrm{Kim}$ (2017) finds that an economy when there are more low-income consumers has a smaller impact of monetary policy on real output, but Cravino, Lan and Levchenko (2018) conclude that a change in the level of inequality does not significantly impact the responses of aggregate prices and output to monetary policy. The main result in the paper contradicts that in Kim (2017) or Cravino, Lan and Levchenko (2018): a more equal economy is associated with more effective monetary policy in terms of output. The finding in this study is supported by empirical papers in the literature such as Alpanda and Zubairy (2017) and Voinea, Lovin and Cojocaru (2018).

${ }^{6}$ In this class of the model, (i) money is directly transferred from a government (or a money authority) to households, (ii) money growth (money supply) shocks are introduced as an instrument of the monetary policy, and (iii) households should hold cash to buy goods and services.

${ }^{7}$ An interplay between a discrete labor choice and wage rigidity will amplify the transmission of monetary policy shocks to the labor market. 
the response of real wages and prices to monetary policy shocks. Thus, aggregate labor supply elasticity, which represents the shape of reservation wage distributions, can be the main linkage between the long-run level of inequality and the effectiveness of monetary policy.

To the best of my knowledge, this model framework is the first that considers a monetary neoclassical model with nominal wage contracts, incomplete asset markets, and rich household heterogeneity.

One of the main findings is that expansionary monetary policy reduces income, consumption, and wealth inequalities. In response to expansionary monetary policy shocks, the nominal wage contract leads to a fall in real wages, ${ }^{8}$ and this allows firms to hire more workers. A rise in employment from the bottom of distributions decreases inequality. There are heterogeneous effects of monetary policy on income across the wealth distribution. The different responses of real wages and real asset returns generate compositional effects of monetary policy on consumers' income. The rich benefit from a rise in the real asset returns while the poor benefit from an increase in employment in a relative sense. There are also asymmetric responses of consumption between the poor and the rich. Households in the bottom of the wealth distribution increase consumption while asset-rich households tend to decrease consumption. This implies that inflation hurts wealthy households more.?

A second important finding is that the long-run level of inequality matters for the effectiveness of monetary policy. The degree of heterogeneity in an economy would determine the size of aggregate labor supply elasticity (or the shape of the reservation wage distribution), which affects the responses of real wages and prices to monetary policy shocks. In an economy with less heterogeneity, labor supply elasticity is larger (or the reservation wage distribution is more concentrated), which implies that relatively more equal households are placed around the market wage. Accordingly, the general equilibrium effect would be bigger: there is a larger decrease in real wages as the price level increases by more, which leads to a bigger response of output. Therefore, a more equal society is associated with more effective monetary policy in terms of output, ceteris paribus. I also provide empirical evidence for

\footnotetext{
${ }^{8}$ There are abundant empirical studies suggesting that real wages are coutercyclical in response to monetary policy shocks. For example, Spencer (1998) provides empirical findings that the real wage response is strongly and robustly negative in response to demand shocks, which supports sticky-wage theories of the business cycle including the model economy in this paper. Similarly, Balmaseda, Dolado and Lopez-Salido (2000) empirically document that real wages are countercyclical in response to aggregate demand shocks. Leiderman (1983) also finds that real wage response to an unanticipated increase in money growth is weakly negative.

${ }^{9}$ This finding is consistent with Doepke and Schneider (2006). Their empirical results suggest that rich and old households hurt more from inflation. Similarly, Wong (2018) finds that consumption of younger people is more responsive to rate shocks.
} 
this model result using state-level panel data: the effects of monetary policy shocks on GDP are larger for low-inequality states.

This paper is organized as follows. Section 2 summarizes the related literature. Section 3 introduces the heterogeneous-agent model economy with indivisible labor and nominal wage contracts. The distributional consequences of monetary policy are discussed in Section 4. Section 5 examines the role of the long-run level of inequality in the effectiveness of monetary policy. Section 6 concludes.

\section{Related Literature}

Some recent papers provide an insightful analysis of redistributive effects of monetary policy. Auclert (2017) investigates redistribution channels of an exogenous monetary policy shock and finds that the effects of monetary policy on aggregate consumption tend to be amplified by such redistribution channels. Kaplan, Moll and Violante (2018) introduce financial market incompleteness in New Keynesian models. In the model of Kaplan, Moll and Violante (2018), there are two types of assets with different degrees of liquidity and different returns. Their model successfully reproduces a wealth distribution, also across liquid and illiquid assets, and a distribution of the marginal propensities to consume (MPC). In this setting, Kaplan, Moll and Violante (2018) find that the indirect effects of an unexpected fall in interest rates, which operate through a general equilibrium (e.g., an increase in labor demand), dominate the direct effects, which are mainly from intertemporal substitution effects. Gornemann, Kuester and Nakajima (2016) consider a model economy in which households differ in their employment status, earnings, and wealth in the context of New Keynesian frameworks and study the importance of the earnings and income composition channels. In their model, matching frictions create countercyclical labor-market risk which is endogenous to monetary policy. Gornemann, Kuester and Nakajima (2016) find that contractionary monetary policy shocks increase inequality since a contractionary shock tends to prolong unemployment spells, as firms reduce labor demand. Another interesting result that they find is that a majority of households prefer substantial stabilization of unemployment even if this means deviations from price stability. ${ }^{10}$ The current paper differs from previous studies in the literature on the transmission mechanism of monetary policy in the presence of incomplete markets in that

\footnotetext{
${ }^{10}$ Werning (2015) also studies some of the channels through which heterogeneity and incomplete markets imply a departure from the aggregate implications of the standard representative agent approach.
} 
(i) this study focuses more on the distributional effects of discretionary changes in monetary policy actions; ${ }^{11}$ (ii) the key monetary transmission mechanism is generated by employment dynamics induced by nominal wage contracts. ${ }^{12}$ There are also some empirical analyses that study how the actions of the monetary authority affect inequality, and contributions are Furceri, Loungani and Zdzienicka (2016) and Coibion et al. (2017). ${ }^{13}$ Their main finding is that a contractionary monetary policy shock increases inequality, which is consistent with the model result in this paper.

Most of the previous literature regarding the relation between inequality and monetary policy have mainly focused on one direction of the relation, the impact of monetary policy on inequality. The other direction, the effect of the long-run level of inequality on the effectiveness of monetary policy, is relatively unstudied. There are a few studies on the role of inequality in the effectiveness of monetary policy. Using retail scanner and consumer panel data, Kim (2017) empirically documents that low-price brands change prices more frequently than high-price brands, and demand for low-price brands has a negative correlation with household income. Using a menu-cost model with vertically differentiated products and heterogeneous consumers, he concludes that the impact of monetary policy on real output decreases when there are more low-income consumers in the economy. Similarly, Cravino, Lan and Levchenko (2018) provide empirical evidence that the estimated impulse responses of high-income households' consumer price indices are lower than those of the middle-income households. Based on a quantitative New-Keynesian model with heterogeneous households where sectors are heterogeneous in their frequency of price changes, they conclude that a realistic change in inequality does not substantially affect the responses of aggregate prices and output to monetary policy. The current paper contributes to the literature by emphasizing the role of different shapes of reservation wage distributions depending on a degree of inequality in the causal relation between inequality and the effectiveness of monetary policy, while Kim (2017) and Cravino, Lan and Levchenko (2018) focus on the channels of different frequency of price changes and heterogeneous composition of consumption goods across households. Because of the different key mechanism from those in Kim (2017) and Cravino, Lan and Levchenko (2018), the

\footnotetext{
${ }^{11}$ The main focus of Gornemann, Kuester and Nakajima (2016) is on the heterogeneous welfare effects of systematic monetary policy while Kaplan, Moll and Violante (2018) decompose the transmission mechanism of monetary policy into direct and indirect general equilibrium effects on aggregate consumption.

${ }^{12}$ The countercyclical labor-market risks created by matching frictions are important for the transmission of monetary policy in Gornemann, Kuester and Nakajima (2016) whereas the key features in Kaplan, Moll and Violante (2018) are multiple assets with different degrees of liquidity and different returns.

${ }^{13}$ Doepke and Schneider (2006) also empirically document the impacts of inflation through changes in the value of nominal assets. Their main finding is that that rich and old households are the main losers from the occurrence of inflation.
} 
main result in the paper contradicts theirs but is supported by empirical papers in the literature such as Alpanda and Zubairy (2017) and Voinea, Lovin and Cojocaru (2018). ${ }^{14}$ This paper is also related to the literature which discusses the relation between the long-run level of inequality and government spending multiplier (Brinca et al., 2016; Yang, 2017) ${ }^{15}$ and studies which investigate an importance of micro-level heterogeneity in the propagation of aggregate shocks (e.g., Werning (2015) and Krueger, Mitman and Perri (2016)). ${ }^{16}$

This study also contributes to the literature by incorporating uninsurable risks into a standard real business cycle model with money. The monetary neoclassical models based on the representative agent have had a lot of success in accounting for many important macroeconomic issues (e.g. Cooley and Hansen (1989), Cho and Cooley (1995), Janko (2008), and Floden (2000)). ${ }^{17}$ However, all these representative-agent models cannot study any macroeconomic questions regarding distributions and inequality. By introducing uninsurable risks and household heterogeneity into a monetary neoclassical model, the current paper investigates not only a propagation of monetary policy shocks to aggregate variables but also the distributional effects of monetary policy actions. Recent studies in the literature, including Ragot (2014) and Camera and Chien (2014), also introduce idiosyncratic shocks in the context of the business cycle models with money. Relative to this literature, the current paper focuses more on the distributional effects of monetary policy. ${ }^{18}$

\footnotetext{
${ }^{14}$ Using Romanian data, Voinea, Lovin and Cojocaru (2018) find a contract result that lower inequality is associated with stronger effectiveness and higher homogeneity of monetary policy transmission. Alpanda and Zubairy (2017) also provide empirical evidence that the effects of monetary policy are less powerful during periods of high household debt.

${ }^{15}$ Brinca et al. (2016) study the relation between wealth inequality and the magnitude of fiscal multipliers. Similarly, Yang (2017) investigates the relationship between income inequality and the local government spending multipliers using rich historical state-level data on military procurement and inequality.

${ }^{16}$ Werning (2015) argues that the effect of market incompleteness on the interest rate elasticity of aggregate demand depends on the cyclicality of liquidity and of income risk. Krueger, Mitman and Perri (2016) study the importance of household heterogeneity for aggregate consumption and output dynamics.

${ }^{17}$ Cooley and Hansen (1989) consider cash-in-advance constraints in the standard real business cycle model to analyze if the business cycle depends on inflation states. Cho and Cooley (1995) extend the model of Cooley and Hansen (1989) by introducing nominal wage contracts and study the quantitative importance of the wage contracts for business cycle fluctuations. In the context of Cho and Cooley (1995), Janko (2008) adds labor adjustment costs into a model with nominal wage rigidity and finds that the model with labor adjustment costs is able to replicate reasonable volatilities of real variables and a countercyclical productivity. Floden (2000) constructs a business cycle model economy in which money supply is set to minimize the volatility of inflation and output and finds that small changes in the preferences of a central bank is able to produce large changes in correlations between real and nominal variables.

${ }^{18}$ Sterk and Tenreyro (2018) also investigate a redistribution channel for the transmission of monetary policy focusing on durable purchases using the heterogeneous-agent model with money, but their model is based on flexible prices.
} 


\section{Model Economy}

I develop a simple dynamic stochastic general equilibrium (DSGE) model which employs a continuum (measure one) of heterogeneous households, a government, and many identical firms. In the model economy, there are four main assumptions. First, asset markets are incomplete as in Huggett (1993) and Aiyagari (1994) in that households cannot fully insure against their idiosyncratic productivity shocks. This assumption along with borrowing constrains helps generate substantial heterogeneity across characteristics of individual households including wealth, income, employment, and consumption. Second, following Hansen (1985), Rogerson (1988) and Chang and Kim (2007), it is assumed that a household indivisibly decides hours of work. As is well-known, extensive margins for time devoted to work play an important role in accounting for the variation in total hours worked. Particularly, once indivisible labor is employed in the incomplete asset market model, the aggregate labor supply elasticity depends on how different individual reservation wages are compared to the market wage (Chang and Kim, 2006). Third, cash-in-advance constraints are considered in the standard real business cycle model as in Cooley and Hansen (1989). In this setup, households should hold money to purchase goods and services. Lastly, as in Cho and Cooley (1995) and Janko (2008), nominal wage contracts are incorporated into the model economy to produce a reasonable propagation of monetary policy shocks. Under the nominal wage contract, labor market dynamics is relatively important in the transmission mechanism of monetary policy actions rather than intertemporal substitution effects.

\subsection{Environment}

\subsubsection{Households}

Each household maximizes her expected lifetime utility over cash goods $c_{1 t}$, credit goods $c_{2 t}$, hours of work $h_{t}$, shown as:

$$
\max \mathbb{E}_{0}\left[\sum_{t=0}^{\infty} \beta^{t}\left(\psi \log c_{1 t}+(1-\psi) \log c_{2 t}-\chi \frac{h_{t}^{1+1 / \phi}}{1+1 / \phi}\right)\right]
$$

subject to 


$$
\begin{gathered}
P_{t} c_{1 t} \leq m_{t-1}+t r_{t}, \\
P_{t}\left(c_{1 t}+c_{2 t}+a_{t+1}\right)+m_{t}=W_{t}^{c} x_{t} h_{t}+\left(P_{t}+R_{t}\right) a_{t}+m_{t-1}+t r_{t},
\end{gathered}
$$

and

$$
a_{t+1} \geq \bar{b}
$$

where $0<\beta<1$ denotes the time discount factor, $\chi>0$ is a parameter for disutility from working, $\psi$ is a weight for cash goods, and $\phi$ represents labor supply elasticity. There are two types of consumption goods in the model economy: one is a cash good (denoted by $c_{1 t}$ ), and the other is a credit good (denoted by $c_{2 t}$ ). When a household wants to purchase cash goods, she is required to hold money. The currency holdings of a household consist of two sources: money balances carried over from the previous period, $m_{t-1}$, and a money transfer from the government, $t r_{t}$. Specifically, a decision on cash goods for a households must satisfy cash-in-advance (CIA) constraints as in Equation 1, where $P_{t}$ is the price level. As in Cooley and Hansen (1989) and others in the literature, it is assumed that the CIA constraint holds with equality. ${ }^{19}$

In addition to the CIA constraint, each household faces the budget constraints as in Equation 2. It is assumed that a household is endowed with one unit of physical time, which she allocates between hours worked and leisure. When a household works for $h_{t}$ amount of hours, she earns $W_{t}^{c} x_{t} h_{t}$ as nominal wage earnings, where $W_{t}^{c}$ is the nominal contract wage rate for the efficiency unit of labor, and $x_{t}$ denotes her labor productivity. Importantly, it is assumed that a labor supply decision made by a household is indivisible following Hansen (1985), Rogerson (1988), and Chang and Kim (2007): a household supplies a fixed amount of hours $\left(h_{t}=\bar{h}\right)$, or she does not work at all $\left(h_{t}=0\right)$. Accordingly, there are two employment status for each household: employment and non-employment. A household can save or borrow by trading a claim for financial assets, $a_{t}$, which yields the nominal

\footnotetext{
${ }^{19}$ As discussed by Cooley and Hansen (1989), a sufficient condition for the CIA to be always binding is that the time discount factor is smaller than the gross growth rate of money supply. In the standard calibration case, this condition is generally satisfied.
} 
rate of return, $R_{t}$. The asset markets are incomplete following Huggett (1993) and Aiyagari (1994): households cannot issue any assets contingent on their future idiosyncratic risks $x$. A household faces a borrowing constraint that limits the fixed amount of debt: the assets holding, $a_{t+1}$, cannot go below

$\bar{b}$ at any time. Since the CIA constraint binds all the time, and cash goods $\left(c_{1 t}\right)$ are determined by the CIA constraint, a household makes decisions of credit goods $\left(c_{2 t}\right)$, asset holdings $\left(a_{t+1}\right)$, and money balances $\left(m_{t}\right)$, given the budget constraint. It is assumed that labor productivity, $x$, follows a stochastic process with transition probabilities $P_{x}\left(x^{\prime} \mid x\right)=\operatorname{Pr}\left(x_{t+1}=x^{\prime} \mid x_{t}=x\right)$ and an AR(1) process in logs:

$$
\ln x^{\prime}=\rho_{x} \ln x+\varepsilon_{x}, \quad \varepsilon_{x} \sim N\left(0, \sigma_{x}^{2}\right) .
$$

Since households face borrowing constraints and asset-market incompleteness, they will behave differently in response to monetary policy shocks, depending on individual state variables.

\subsubsection{Firms}

The production technology for the representative firms is represented by the function given by:

$$
F(K, L, Z) \equiv Z K^{\alpha} L^{1-\alpha}
$$

where $Z, K, L$ and $\alpha$ denote aggregate productivity, aggregate capital, aggregate effective labor, capital income share, respectively. Given the contract wages, the representative firm makes decisions for labor and capital demand to maximize current profits such that:

$$
\left.\Pi_{t}=\max _{K_{t}, L_{t}}\left\{P_{t} Z_{t} K_{t}^{\alpha} L_{t}^{1-\alpha}-W_{t}^{c} L_{t}-R_{t} K_{t}-P_{t} \delta K_{t}\right)\right\}
$$

where $\delta$ is the real depreciation rate for capital.

\subsubsection{The Government}

The government takes up the role of printing money and injecting it into the economy, and it faces the constraint:

$$
P_{t} G_{t}+T_{t}=M_{t}-M_{t-1},
$$


where $G_{t}$ is real government expenditure, $T_{t}$ is total nominal transfer, and $M_{t}$ is money supply. Since this study does not focus on the impact of changes in government spending, it is assumed that $G_{t}$ is constant over time. ${ }^{20}$ Accordingly, the total nominal transfer can be directly financed by changing money supply. The government issues money according to the following rule:

$$
M_{t+1}=g_{t+1} M_{t}
$$

where $g_{t+1}$ is the gross growth rate of money between periods $t$ and $t+1 . g_{t+1}$ is assumed to evolve according to the autoregression of the form:

$$
\log \left(g_{t+1}\right)=\rho_{g} \log \left(g_{t}\right)+\omega_{t+1}
$$

and

$$
\omega_{t+1} \sim N\left(\left(1-\rho_{g}\right) \log (\bar{g}), \sigma_{g}^{2}\right),
$$

where $\bar{g}$ represents the gross growth rate of money in the steady state. As mentioned above, $\mathbb{E}_{t}\left[1 / g_{t+1}\right]<1 / \beta$ implies that the CIA constraint is binding in every period.

\subsubsection{Nominal Wage Contract}

A nominal rigidity is introduced into the model economy in order to obtain reasonable effects of monetary policy and to see the importance of labor market for the propagation of monetary policy. In the model economy, nominal wage rigidity arises from nominal wage contracts agreed to by households and firms. In this paper, a "contract" means that households and firms set up rules and agree to follow them. There are three rules in the wage contract: a wage setting rule, a labor input setting rule, and an employment allocation rule. The first two are agreements between the firms and households while the last one is a rule among households. The wage setting rule and the labor input setting rule will be discussed in this section, and the employment allocation rule will be followed the households' problem.

Wage Setting Rule The nominal contract wage rate is determined by both desired wages and previous contract wages. I use a natural formulation of the contract wages as a weighted average (in logs) of the wage in the previous period and the desired wage. Formally, the nominal contract wage rate, $W_{t}^{c}$, is given by:

\footnotetext{
${ }^{20} \mathrm{Without}$ loss of generality, $G_{t}$ is assumed to be zero in every time period.
} 


$$
W_{t}^{c}=\left(W_{t}^{o}\right)^{1-\lambda}\left(W_{t-1}^{c}\right)^{\lambda}
$$

where $W_{t}^{o}$ is the nominal desired wage rate, and $\lambda$ is the nominal wage rigidity index. Under this assumption, an important issue is how to determine the desired nominal wages. Regarding this issue, I assume that the nominal desired wages follow the pricing rule from the frictionless economy where nominal wage contracts are omitted (Cho and Cooley, 1995; Janko, 2007). Specifically, as in Chang and Kim (2007), the forecasting function for the market wage rate is assumed to take log-linear functions of aggregate state variables, $K_{t}$ and $g_{t} \cdot{ }^{21}$ Hence, the nominal desired wage, $W_{t}^{o}$, is given by:

$$
\log \left(W_{t}^{o}\right)=\gamma_{1}+\gamma_{2} \log \left(K_{t}\right)+\gamma_{3} \log \left(g_{t}\right)
$$

where $K_{t}$ is the aggregate capital. Note that the coefficients $\left(\gamma_{1}, \gamma_{2}\right.$, and $\left.\gamma_{3}\right)$ in the forecasting function are estimated from the economy without the nominal wage contract. The assumption of desired wages has two interesting features. First, even if the coefficients are exogenously given, the path of nominal desired wages is endogenously determined since the series of aggregate capital, $K_{t}$, is an outcome in the economy with nominal wage contracts. Second, if there is no a wage contract in the model economy $(\lambda=0)$, then the desired wage collapses to the market-equilibrium wage in the frictionless economy, and so does the contract wage.

Labor Input Setting Rule Since the contract wage rates are not equal to the equilibrium ones, it is also important who decides the aggregate labor input. Following Cho and Cooley (1995), Floden (2000), and Janko (2008), I assume that it is the representative firm that determines aggregate effective labor once aggregate shocks are realized. In other words, by agreeing to a nominal contract wage, households cede the right to choose the total efficiency unit of labor to the firms.

\footnotetext{
${ }^{21}$ As found in Krusell and Smith (1998), a very high precision can be obtained by approximating the distribution across characteristics of households using the first moment (mean asset, $K$ ) of it.
} 


\subsubsection{Timing}

The timing assumptions of the model is summarized in Figure 1. Households enter with their own asset and money holdings $(a, m)$ brought from the previous period. Then individual labor productivity shocks, $x$, and the aggregate money supply shocks, $g$, are realized. Observing these shocks, firms and households conclude a nominal wage contract. Given the nominal contract wage, $W^{c}$, the firms make decisions on aggregate effective labor, $L^{c}$. Households then make decisions of their employment first and determine consumption, asset and money holdings next. The details on the households' problem will be discussed in the next subsection.

Figure 1: Timing of Event

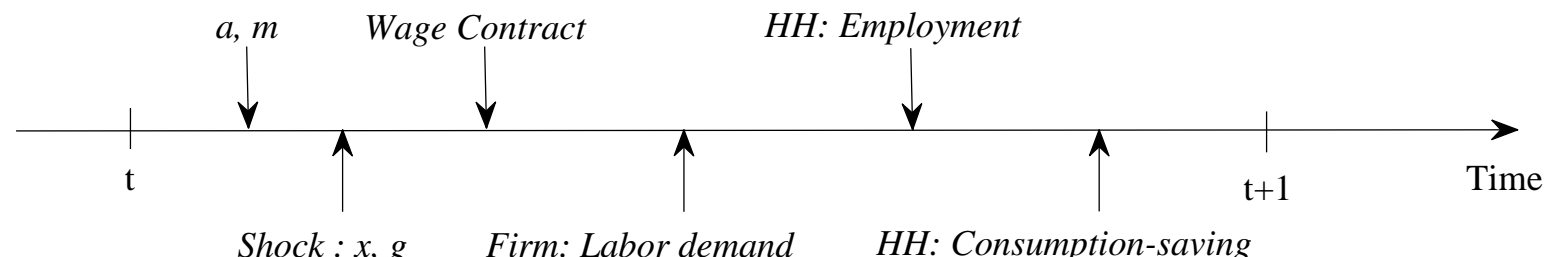

Note: The figure presents the timing of the event for the model economy. "HH" denotes "households."

\subsection{Household Problem}

Under the wage contract, households should provide the efficiency units of labor that the firm demands since they agree to cede the right to decide the aggregate effective labor to the representative firm. In the representative-agent model, it is easy to fulfill the wage contract for the representative household since all identical households are employed and supply the same amount of labor. In the heterogeneous-agent model economy, however, the "employment allocation rule"-how different households allocate their hours-matters given the aggregate effective labor and the contract wages since reservation wages are different across households. Since the employment status of a household affects her consumption and saving decisions, a reasonable assumption of labor supply decisions for households is a critical issue. To this end, I introduce two sequential steps for households' problems. The first step is the employment allocation rule. I assume that in the first step, given the wage contract (or the aggregate effective labor), households make a decision on their employment. In the second step, 
given the wage contract and the employment decisions, households decide how much they consume and save. The two steps are summarized as follows:

- Step 1 (Employment decision): given the wage contract, households make a decision on employment (the employment allocation rule).

- Step 2 (Consumption-saving decision): given the wage contract and employment decisions, households make consumption-saving decisions.

\subsubsection{Reservation Wages}

Before discussing how households allocates hours in the model economy with the nominal wage contract, it is useful to consider households' employment decisions in the frictionless economy. In the model economy with indivisible labor, a reservation wage rate (per effect labor) is an important concept for households to make their employment decisions. Define $\theta$ and $\Theta$ as the vector of individual and aggregate state variables, respectively: $\theta \equiv(a, m, x)$ and $\Theta \equiv(\mu, g)$, where $\mu(\theta)$ is the type distribution of households. ${ }^{22}$ Let me consider the labor supply decision for a household. Since the labor supply choice is assumed to be indivisible $\left(h_{t}=\bar{h}\right.$ or $\left.h_{t}=0\right)$, there are two employment status for a household: a household is employed or non-employed. The value function for an employed household, denoted by $V^{E}(\theta, \Theta)$, is defined as:

$$
V^{E}(\theta, \Theta)=\max _{c_{1}, c_{2}, a^{\prime}, m^{\prime}}\left\{\psi \ln c_{1}+(1-\psi) \ln c_{2}-\chi \frac{\bar{h}^{1+1 / \phi}}{1+1 / \phi}+\beta \mathbb{E}\left[V\left(\theta^{\prime}, \Theta^{\prime}\right)\right]\right\}
$$

subject to

$$
\begin{gathered}
P c_{1} \leq m+t r \\
P\left(c_{1}+c_{2}+a^{\prime}\right)+m^{\prime}=W^{M} x \bar{h}+(P+R) a+m+t r, a^{\prime} \geq \bar{b}
\end{gathered}
$$

and

$$
\mu^{\prime}=\Psi(\Theta)
$$

\footnotetext{
${ }^{22}$ Denote $\mathcal{A}, \mathcal{M}$, and $\mathcal{X}$ for sets of all possible realizations of $a, m$ and $x$, respectively. Then, the measure $\mu(a, m, x)$ is defined over a $\sigma$-algebra of $\mathcal{A} \times \mathcal{M} \times \mathcal{X}$.
} 
where $W^{M}$ is the nominal market wage rate, and $\Psi$ denotes a forecasting function for $\mu$. To simplify notation, time subindices are suppressed, and primes denote variables in the next period. The value function for a non-employed household, denoted by $V^{N}(\theta, \Theta)$, is defined as:

$$
V^{N}(\theta, \Theta)=\max _{c_{1}, c_{2}, a^{\prime}, m^{\prime}}\left\{\psi \ln c_{1}+(1-\psi) \ln c_{2}+\beta \mathbb{E}\left[V\left(\theta^{\prime}, \Theta^{\prime}\right)\right]\right\}
$$

subject to

$$
\begin{gathered}
P c_{1} \leq m+t r \\
P\left(c_{1}+c_{2}+a^{\prime}\right)+m^{\prime}=(P+R) a+m+t r, a^{\prime} \geq \bar{b}
\end{gathered}
$$

and

$$
\mu^{\prime}=\Psi(\Theta)
$$

Then, the employment decision, $h(\theta, \Theta)$, for a household is:

$$
\max _{h \in\{0, \bar{h}\}}\left\{V^{E}(\theta, \Theta), V^{N}(\theta, \Theta)\right\}
$$

The reservation wage rate, denoted by $W^{R}(\theta, \Theta)$, is an individual subjective nominal wage rate (per effective labor) which makes values when working and not working indifferent. Formally, under $W^{R}(\theta, \Theta)$, a value function for an employed household, $V^{E}(\theta, \Theta)$, and a value function for a nonemployed household, $V^{N}(\theta, \Theta)$, are the same. In the frictionless economy, a household is employed if the nominal market wage rate (per effective labor), $W^{M}$, is equal to or larger than her nominal reservation wage rate (per effect labor), $W^{R}(\theta, \Theta)$. That is,

$$
h(\theta, \Theta)=\left\{\begin{array}{cc}
\bar{h} & \text { if } W^{M} \geq W^{R}(\theta, \Theta) \\
0 & \text { otherwise }
\end{array}\right.
$$

Importantly, the reservation wage rate is different across households, depending on net wealth and productivity. ${ }^{23}$ Intuitively, $W^{R}(\theta, \Theta)$ is a decreasing function of labor productivity, $x$, and an

\footnotetext{
${ }^{23}$ Of course, it is also dependent on aggregate states in the economy.
} 
increasing function of asset holdings, $a .^{24}$ Accordingly, a household with a lower reservation wage, or with higher productivity and smaller amount of assets is more likely to be employed in the frictionless economy.

\subsubsection{Employment Decision (Employment Allocation Rule)}

Next, the employment allocation rule is discussed as follows: how heterogeneous households determine their employment under the wage contract. Since the contract wage depends on the contract wage in the previous period, now define $\Theta \equiv\left(\mu, g, W_{-1}^{C}\right)$, where $W_{-1}^{C}$ is the contract wage in the previous period. I assume that given the wage contract, households make a decision on their employment first before making consumption-saving decisions. By agreeing to cede the right to decide an aggregate efficient labor to the representative firm, households should provide effective labor that the firm demands. The aggregate effective labor associated with $W^{c}$ (the current nominal contract wage) is denoted by $L^{c}$. Suppose that $\widetilde{W}$ is the wage rate at which households endogenously provide effective labor of $L^{c}$. Note that $\widetilde{W}$ is different from $W^{c}$ but a function of $W^{c}$. In order to fulfill the wage contract, a household, whose reservation wage rate is less than or equal to $\widetilde{W}$, should work. Formally, now the employment decision for a household is given by:

$$
h(\theta, \Theta)=\left\{\begin{array}{cc}
\bar{h} & \text { if } \widetilde{W} \geq W^{R}(\theta, \Theta) \\
0 & \text { otherwise }
\end{array}\right.
$$

In other words, households solve Equation 5 under $\widetilde{W}$ instead of $W^{M} \cdot{ }^{25}$ With the fulfillment of the wage contract, the following condition must be satisfied:

$$
L^{c}(\Theta)=\int x h(\theta, \Theta) d \mu \text {. }
$$

It should be noted that even if employment decisions are made endogenously under $\widetilde{W}$, some are voluntarily (non-)employed while others are involuntarily (non-)employed because of the wage contracts. Of course, the size of the involuntary labor choices depends on aggregate states in the economy and the wage rigidity index. As discuss above, this is a reasonable assumption of employment

\footnotetext{
${ }^{24}$ In the next section, I will discuss the distribution of the reservation wage rate over individual state variables.

${ }^{25}$ Note that $V(\theta, \Theta)$ is determined in the second step (after $h(\theta, \Theta)$ is obtained) in the model with the wage contract while $V(\theta, \Theta)$ and $h(\theta, \Theta)$ will be jointly determined in the frictionless economy.
} 
decisions for households is that households are employed in ascending order by their reservation wage rates (per effective labor) until they provide $L^{c}$ as in the economy with no wage contracts.

\subsubsection{Consumption-saving Decision}

In the second step, given the wage contract and the employment decisions, households decide how much they consume and save. It is assumed that given employment status, $h(\theta, \Theta)$, decisions for $c_{1}$, $c_{2}, a^{\prime}$, and $m^{\prime}$ are made under the contract wage, $W^{c}$, such that:

$$
V(\theta, \Theta)=\max _{c_{1}, c_{2}, a^{\prime}, m^{\prime}}\left\{\psi \ln c_{1}+(1-\psi) \ln c_{2}-\chi \frac{h(\theta, \Theta)^{1+1 / \phi}}{1+1 / \phi}+\beta \mathbb{E}\left[V\left(\theta^{\prime}, \Theta^{\prime}\right)\right]\right\}
$$

subject to

$$
\begin{gathered}
P c_{1} \leq m+t r \\
P\left(c_{1}+c_{2}+a^{\prime}\right)+m^{\prime}=W^{c} x h(\theta, \Theta)+(P+R) a+m+t r, a^{\prime} \geq \bar{b}
\end{gathered}
$$

and

$$
\mu^{\prime}=\Psi(\Theta)
$$

To sum up, the employment decisions, $h(\theta, \Theta)$, are made under $\widetilde{W}$ to fulfill the wage contract (to supply the effective labor that the firm demands), while consumption-investment decisions $\left(c_{2}(\theta, \Theta), a^{\prime}(\theta, \Theta)\right.$ and $\left.m^{\prime}(\theta, \Theta)\right)$ are made under $W^{c}$.

\subsection{Definition of Equilibrium}

A recursive competitive equilibrium is a transition operator $\Psi(\Theta)$, a set of factors $\left\{K(\Theta), L^{c}(\Theta)\right\}$, a set of value functions $\left\{V^{E}(\theta, \Theta), V^{N}(\theta, \Theta), V(\theta, \Theta)\right\}$, a set of prices $\left\{W^{C}(\Theta), \widetilde{W}(\Theta), P(\Theta), R(\Theta)\right\}$, and a set of policy functions $\left\{c_{1}(\theta, \Theta), c_{2}(\theta, \Theta), m^{\prime}(\theta, \Theta), a^{\prime}(\theta, \Theta), h(\theta, \Theta)\right\}$ such that:

1. Nominal wage contracts

- Contract wage setting rule:

$$
W^{c}=\left(W^{o}\right)^{1-\lambda}\left(W_{-1}^{c}\right)^{\lambda}
$$


- A household, whose reservation wage rate is less than or equal to $\widetilde{W}$, should work, i.e.,

$$
h(\theta, \Theta)=\bar{h} \text { if } \widetilde{W} \geq W^{R}(\theta, \Theta) .
$$

- Households supply the effective labor that the firm demands:

$$
L^{c}(\Theta)=\int x h(\theta, \Theta) d \mu
$$

2. Individual optimization: given $W^{c}$ and $h(\theta, \Theta)$, optimal decision rules $c_{1}(\theta, \Theta), c_{2}(\theta, \Theta), a^{\prime}(\theta, \Theta)$, and $m^{\prime}(\theta, \Theta)$ solve the Bellman equation, $V(\theta, \Theta)$.

3. The firm's profit maximization: given $W^{c}, K(\Theta)$ and $L^{c}(\Theta)$ satisfy $F_{L}\left(K, L^{c}\right)=\frac{W^{c}(\Theta)}{P(\Theta)}$ and $F_{K}\left(K, L^{c}\right)-\delta=\frac{R(\Theta)}{P(\Theta)}$ for all $\Theta$.

4. Markets clearing: for all $\Theta$,

- capital market clearing: $K(\Theta)=\int a d \mu$, and

- goods market clearing: $Z K(\Theta)^{\alpha} L^{c}(\Theta)^{1-\alpha}=C(\Theta)+I(\Theta)$ where $C(\Theta)=\int c_{1}(\theta, \Theta) d \mu+$ $\int c_{2}(\theta, \Theta) d \mu$, and $I(\Theta)=K^{\prime}(\Theta)-(1-\delta) K(\Theta)$.

5. Balanced budget of the government: $P G+T=M^{\prime}-M$.

6. Consistency of individual and aggregate behaviors: for all $A^{0} \subset \mathcal{A}, M^{0} \subset \mathcal{M}$, and $X^{0} \subset \mathcal{X}$,

$$
\mu^{\prime}\left(A^{0}, M^{0}, X^{0}\right)=\int_{A^{0}, M^{0}, X^{0}}\left\{\int_{\mathcal{A}, \mathcal{M}, \mathcal{X}} \mathbf{1}_{a^{\prime}=a^{\prime}(\theta, \Theta), m^{\prime}=m^{\prime}(\theta, \Theta)} d P_{x}\left(x^{\prime} \mid x\right) d \mu\right\} d a^{\prime} d m^{\prime} d x^{\prime}
$$

\subsection{Calibration}

In this section, I discuss calibration for the parameters used in the model economy. A simulation period is a quarter in the model. Table 1 summarizes the parameter values used in the model economy. 


\subsubsection{Preference}

The parameter $\phi$, which represents the micro elasticity of labor supply, is set to 0.4 . This value is based on the findings that conventional micro estimates of the elasticity of labor supply are small $(0-0.5)$. Since labor supply is assumed to be discrete, the value of $\phi$ does not affect the aggregate labor-supply elasticity, and it is determined by the shape of the reservation-wage distribution. According to the Michigan Time-Use Survey, a typical household spends around one third of her discretionary time for working. Hence, fixed amount of hours worked, $\bar{h}$, is chosen to be $1 / 3$. The time discount factor, $\beta$, and the disutility parameter of working, $\chi$, are set so that quarterly return to capital is one percent, and the employment rate is 60 percent, respectively. ${ }^{26}$ The U.S. data such as the PSID and Survey of Consumer Finances (SCF) consistently report that employment rates are around 60 percent. ${ }^{27}$ According to Bagnall et al. (2016), the share of payments by value done with cash by US consumers is 23 percent, and the share of average transaction values done with cash is 17.8 percent. Based on these measures, the parameter for the share of cash goods, $\psi$, is chosen to be 20 percent.

\subsubsection{Production and Borrowing Constraint}

Parameter values for production are quite standard. Since this study does not focus on the impact of aggregate productivity shocks, it is assumed that $Z_{t}$ is constant at 1 over time. The capital income share, $\alpha$, and the quarterly depreciation rate, $\delta$, are calibrated to be 0.36 and 2.5 percent, respectively. The borrowing constraint, $\bar{b}$, is -3.0 , which is approximately twice of the quarterly average earnings in the model economy. ${ }^{28}$ With this value, the fraction of households who own zero or negative wealth is around 20 percent, which is consistent with that in the U.S. data such as the PSID.

\subsubsection{Labor Productivity}

For individual labor productivity shocks, previous studies in the literature including Floden and Linde (2001), Chang and Kim (2006), and Chang, Kim and Schorfheide (2013) consistently report that the shocks are persistent, and the variance is also large. Following Chang, Kim and Schorfheide (2013), I

\footnotetext{
${ }^{26}$ The discount factor, $\beta$, in the heterogeneous-agent model is smaller than that in the representative-agent model, because market incompleteness makes households increase precautionary savings as noted in Aiyagari (1994).

${ }^{27}$ Self-employed workers are excluded for the calculation of employment rates.

${ }^{28}$ Similarly, Chang and Kim (2006) also choose the borrowing constraint to target one and a half of quarterly earnings for a household who has the average-productivity.
} 
Table 1: Parameters of the Model Economy

\begin{tabular}{crll}
\hline \hline Parameter & Value & Description & Source/Target Moments \\
\hline \multicolumn{1}{c}{} & & \multicolumn{2}{c}{ Literature or Data Directly } \\
$\phi$ & $1 / 3$ & Extensive margin for hours worked & Standard \\
$\psi$ & 0.4 & Labor supply elasticity & Standard \\
$\rho_{x}$ & 0.20 & Share of cash goods & Bagnall et al. (2016) \\
$\sigma_{x}$ & 0.939 & Persistence of $x$ shocks & Chang, Kim and Schorfheide (2013) \\
$\delta$ & 0.287 & Standard deviation of $x$ shocks & Chang, Kim and Schorfheide (2013) \\
$\alpha$ & 0.025 & Capital depreciation rate & Standard \\
$\rho_{g}$ & 0.36 & Capital income share & Standard \\
$\sigma_{g}$ & 0.8 & Persistence of $g$ shocks & Christiano (1991) \\
$\bar{g}$ & 0.004 & Standard deviation of $g$ shocks & Christiano (1991) \\
$\lambda$ & 1.012 & Steady state $g$ & Janko (2008) \\
& 0.8 & Wage rigidity index & Smets and Wouters (2003)
\end{tabular}

\section{Calibrated}

$\beta \quad 0.97782$ Time discount factor Real return to capital

$\bar{b} \quad-3.0 \quad$ Borrowing constraint Doubled average quarterly earnings

$\chi \quad 145.8 \quad$ Parameter for disutility from working Employment rate

Note: The table summarizes the parameter values used in the model economy. Parameters in the upper panel are from the literature or data directly while parameters in the bottom panel are chosen to match data moments.

set $\rho_{x}=0.939$ and $\sigma_{x}=0.287$, which are estimated with the AR(1) wage process from the PSID. ${ }^{29}$ The number of grids for labor productivity is 15 . Grid vectors of productivity are equally spaced in which $\ln x$ lies between $-3 \sigma_{x} \sqrt{1-\rho_{x}^{2}}$ and $3 \sigma_{x} \sqrt{1-\rho_{x}^{2}}$. Transition probabilities of productivity are approximated using Tauchen (1986) algorithm and are shown in Table A.1.

Table 2: Transition Probabilities for Money Supply Shock

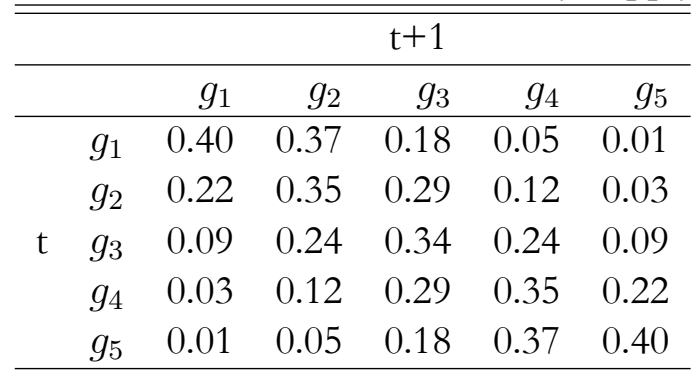

Note: Transition probabilities per quarter. $g_{i}$ denotes a money growth grid $i$. Rounding for the table means rows may not sum to 1.

\footnotetext{
${ }^{29}$ Chang, Kim and Schorfheide (2013) use the maximum-likelihood estimation (MLE) when they estimate the AR(1) process of wage rates in logs to solve the self-selection problem for wage workers.
} 


\subsubsection{Money Supply and Wage Contract}

Regarding the money supply shocks, Christiano (1991) estimate values for the parameters of the money growth process, $\rho_{g}$ and $\sigma_{g}$, using the U.S. time series data. Following his estimate, I choose $\rho_{g}=$ 0.8 and $\sigma_{g}=0.004$. The steady-state rate of gross money growth is assumed to be $1.015 .^{30}$ The number of grids for money growth is 5 . Grid vectors of productivity are equally spaced in which $\ln g$ lies between $-3 \sigma_{g} \sqrt{1-\rho_{g}^{2}}$ and $3 \sigma_{g} \sqrt{1-\rho_{g}^{2}}$. Transition probabilities of money growth are also approximated using Tauchen (1986) algorithm and are shown in Table 2. The index for nominal wage rigidity is set to 0.8 , which is in the range of the values typically used in the literature. For example, Smets and Wouters (2003) estimate a degree of nominal wage sickness and find that it is 0.74, which is the median in the posterity distribution.

Table 3: Key Aggregate Moments

\begin{tabular}{lcc}
\hline \hline Moment & Data & Model \\
\hline \multicolumn{3}{c}{ Targeted Moment } \\
Employment rate & 0.60 & 0.60 \\
Real capital return & 0.01 & 0.01 \\
\multicolumn{3}{c}{ Untargeted Moment } \\
Income Gini & 0.57 & 0.59 \\
Wealth Gini & 0.78 & 0.68 \\
Consumption Gini & 0.30 & 0.33 \\
Flow out of employment & 6.82 & 5.60 \\
Flow into employment & 7.01 & 5.60 \\
\hline
\end{tabular}

Note: Information for income and wealth in the data are from Diaz-Gimenez, Quadrini and Rios-Rull (1997), while statistics for consumption is the Consumer Expenditures Survey (CEX) average for the period 1980-2008. The measure for the employment flows is from the working paper of Chang and $\operatorname{Kim}(2006)$.

\section{The Effects of Monetary Policy on Inequality}

\footnotetext{
${ }^{30}$ This value is very standard in the literature. For example, Janko (2008) find that the estimate of the parameter value is 1.012.
} 


\subsection{Aggregate Moments and Cross-sectional Distributions}

First, I present the main results of aggregate moments. I summarize the data and the model counterparts of the targeted (upper panel) and untargeted moments (bottom panel) in Table 3. The model economy fits well the targeted moments by construction, thus we mainly examine the fit of the model to the data in terms of the untargeted moments. Table 4 summarizes the shares of income, wealth and consumption for the data and the model economy. The model economy reasonably replicates the income distribution of the U.S., making the income Gini index of the simulated model 0.59, which is comparable to the data (0.57). The inequality of wealth distribution in the model economy is less concentrated compared to the U.S. data: the model economy makes the wealth Gini index about 0.68 while it is 0.78 in the U.S. data. Consumption inequality is also well replicated by the model: Gini index for consumption is 0.33 in the model, which is similar to what is observed in the U.S. data (0.30). In the U.S data, on average, 6.82 percent of the population moved from employment to nonemployment each quarter; 7.01 percent of the population moved in the opposite direction, from nonemployment to employment. In the model, these flows are 5.60 percent. Although I do not calibrate the model to match these values, the worker flows are fairly close to those in the U.S. data.

Table 4: Three Key Distributions

\begin{tabular}{lrrrrrr}
\hline \hline & 1st & 2nd & 3rd & 4th & 5th & Gini \\
\cline { 2 - 7 } & 2.18 & 6.63 & 11.80 & 19.47 & 59.91 & 0.57 \\
Share of Income & -0.39 & 1.74 & 5.72 & 13.43 & 79.49 & 0.78 \\
Share of Wealth & 11.02 & 15.07 & 18.07 & 22.53 & 33.31 & 0.30 \\
Share of Consumption & \multicolumn{7}{c}{ Model Economy } & & & \\
& 0.81 & 4.57 & 11.15 & 23.10 & 60.37 & 0.59 \\
Share of Income & -2.70 & 2.00 & 10.00 & 24.55 & 66.15 & 0.68 \\
Share of Wealth & 6.49 & 12.50 & 17.57 & 24.02 & 39.42 & 0.33 \\
Share of Consumption
\end{tabular}

Note: Information for income and wealth in the data are from the Survey of Consumer Finances (SCF) 1992 in Diaz-Gimenez, Quadrini and Rios-Rull (1997), while statistics for consumption is the Consumer Expenditures Survey (CEX) average for the period 1968-2015. 


\subsection{The Aggregate Effects of Monetary Policy}

In this subsection, I discuss the transmission of an expansionary one-standard-deviation monetary policy shock (positive money growth shocks). The responses of key aggregate variables in the model economy to a one-standard-deviation monetary policy (money growth) shocks for 20 quarters of horizon are shown in Figure 2. The mechanism of the effects of an unexpected rise in money supply on real economic activity in the model is through the nominal wage contract. An unexpected rise in the money growth leads to a higher price level: it increases by 0.20 percentage. ${ }^{31}$ Accordingly, real wages drop (by 0.16 percent), and real capital returns increase (by 0.99 percent points) due to the nominal wage contract. A fall in the rental price for labor allows the firms to hire more workers. Accordingly, hours (employment) and output increase significantly (by 0.82 percent and 0.32 percent, respectively). A rise in price level decreases demand for cash goods, while credit goods increase because of a rise in income, which leads to a smoothly rise in total consumption. Total consumption rises by 0.03 percent at the peak. It should be also noted that a rise in involuntary employment also contributes to an increase in credit goods since households who are forced to work by the wage contract increase their consumption to compensate for increased disutility from working. Investment also increases markedly (by 1.41 percent) due to a portfolio change caused by the higher price level and a rise in the real asset return. ${ }^{32}$ The dynamics of most of the macro variables in the model economy is well supported by empirical studies in the literature including Christiano, Eichenbaum and Evans (2005).

\subsection{Heterogeneous-agent vs. Representative-agent Models}

At this stage in the analysis, one question may arise: what is the difference between the heterogeneousagent model (HA model) and the representative-agent model (RA model) which has been studied in the previous literature? The basic assumptions for the nominal wage contacts in the RA model are the same as those in the HA model other than the employment decisions for households. In the RA model, households are not able to decide who works or not as in the HA model since they are assumed to be identical. Hence, I assume that in the RA model, given the contract wage, all the identical households

\footnotetext{
${ }^{31}$ Following studies in the literature (e.g., Cho and Cooley (1995) and Floden (2000)), the price level is divided by aggregate money stock to make it stationary.

${ }^{32}$ Of course, a rise in total income also contributes to an increase in investment.
} 

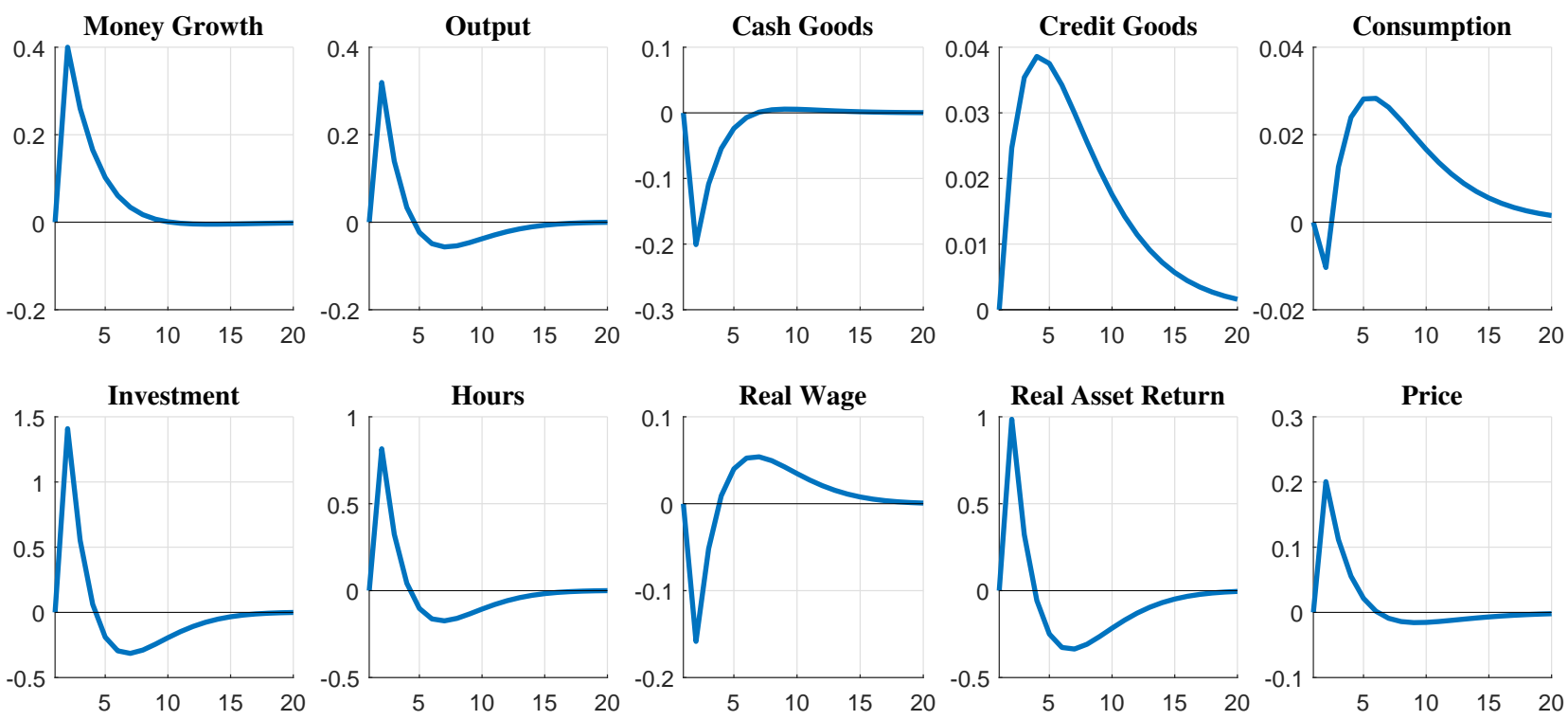

Figure 2: Impulse-responses of Aggregate Variables

Note: Impulse response to a one-standard-deviation monetary policy (money growth) shock. All variables other than interest rates are logged. The $\mathrm{x}$-axis shows time since the shock in quarters.

provide $L^{c}$, which is determined by firm's profit maximization condition. This assumption is widely used in the literature such as Cho and Cooley (1995), Floden (2000), and Janko (2008). For calibration strategy for the RA model, I choose $\beta=0.99$ to match a one percent quarterly return to capital, and disutility parameter of working, $\chi$, is chosen to target the aggregate hours of 0.2 , as in the HA model (60 employment rate $\times 1 / 3$ ). Importantly, the labor supply elasticity, $\phi$, is chosen to be 1.14 , which is the same as the aggregate labor supply elasticity generated by the HA model. ${ }^{33}$

Figure 3 presents the impact of a one-standard-deviation expansionary monetary shock for the HA model and the RA model. The solid lines show the response in the economy with heterogeneous households, while the dotted lines report the response in the economy with a representative household. A striking feature in the HA model is that hours increase significantly by more than those in the RA model, even though the model economies are assumed to have the same aggregate labor supply elasticity. The difference is mainly due to how households allocate their hours in the two economies. In both models, by agreeing to a nominal contract wage, households should supply the total efficiency unit of labor that the firms want. What is different in the two models is how households make decisions of their labor supply. In the HA model, it is assumed that households are employed in ascending order by their reservation wage rates (per effective labor) until they provide $L^{c}$. Hence, households whose

\footnotetext{
${ }^{33}$ Chang and Kim (2007) also use the same calibration strategy for their RA model.
} 
reservation wage rates are slightly higher than the contract wage tend to be newly employed. Since the reservation wage is a decreasing function of productivity, less productive households newly work. Accordingly, given the demand for aggregate effective labor, more employed households are needed in the HA model to fulfill the wage contract since newly employed households are less productive. In the RA counterpart, however, all the households have the same productivity, which is the average productivity in the HA model. The efficient unit of labor provided by the newly employed households in the RA model is larger than that in the HA model. Hence, hours increase significantly by less in the RA model compared to those in the HA model.
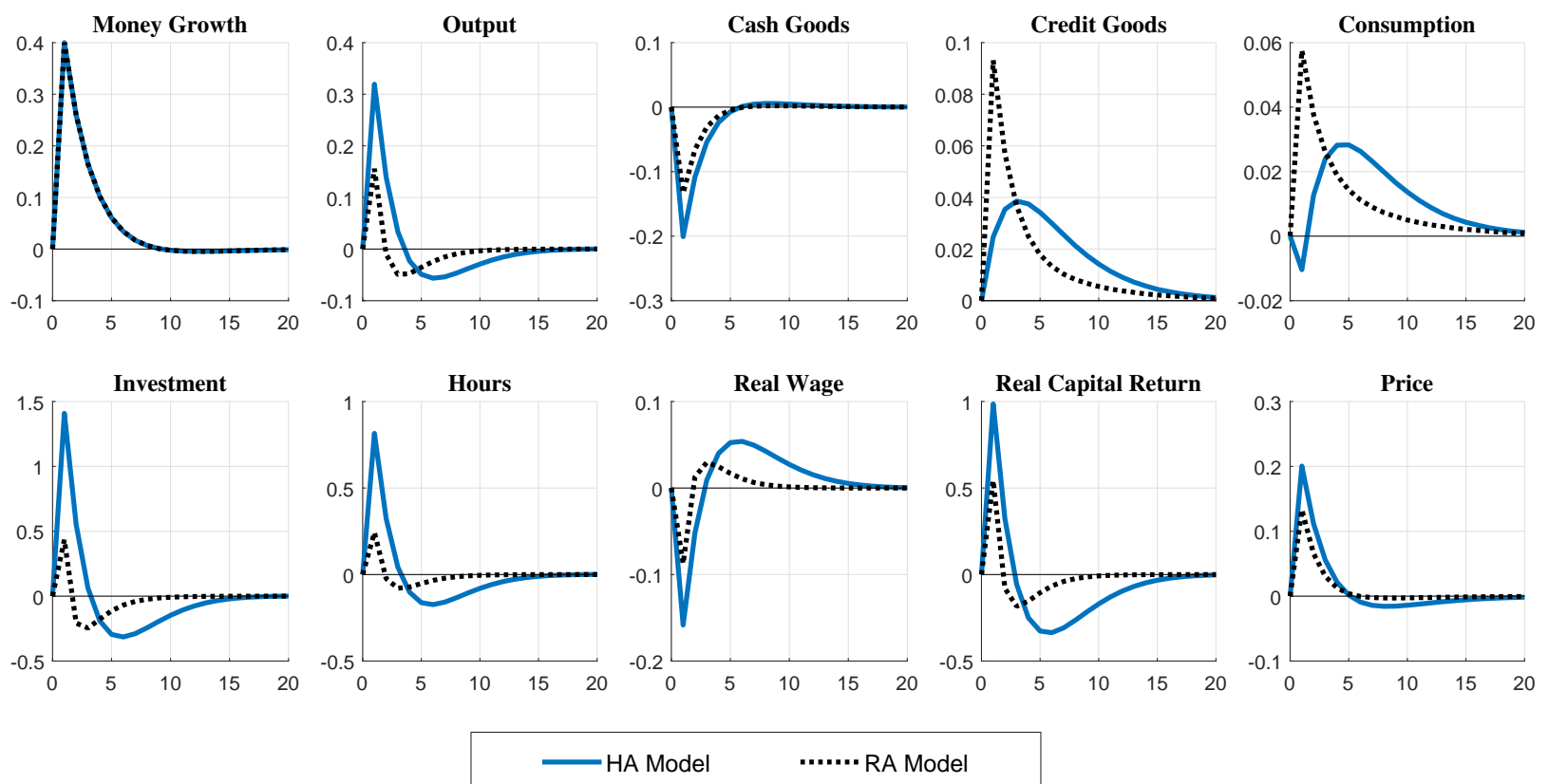

Figure 3: Impulse-responses of Aggregate Variables: HA vs. RA models

Note: Impulse response to a one-standard-deviation monetary policy (money growth) shock. All variables other than interest rates are logged. The x-axis shows time since the shock in quarters. The solid blue lines show the response in the economy with heterogeneous households, while the dotted lines report the response in the economy with a representative household.

Another interesting feature is that households in the HA model have a smoother consumption path than those in the RA counterpart. Households who are forced to work by the wage contract are likely to increase their consumption to compensate for the reduction of utility from involuntarily working. In the RA model, consumption will increase by more than that in the HA model since every household is forced to work more. However, credits goods do not jump substantially in the HA model since consumption dynamics is not only affected by households who work involuntarily, and precautionary saving behaviors of voluntary workers stop credits goods from increasing by more. ${ }^{34}$ As found in

\footnotetext{
${ }^{34}$ Intuitively, aggregate response of credit goods depend on the marginal worker distribution in the economy. I will
} 
Figure 3, credit goods in the RA model dramatically increase on impact while those in the HA model have a relatively smooth path. In the RA model, at the cost of a rise in consumption on impact, investment increases by less than that of the HA counterpart. On net, output on impact rises by more in the HA economy than that in the RA economy. Additional general equilibrium effects also play important a role in generating the larger of output in the HA model. A money demand also increases by more in the HA model than that in the RA counterpart due to the smooth consumption response, which leads to a larger increase in the price level and output in the HA model.

\subsection{Behaviors of Marginal Workers}

In response to an unexpected monetary expansion, by agreeing to the nominal wage contract, households whose reservation wage rates are closed to contract wage are employed since they should supply the total efficiency unit of labor that the firms demand. Households who are newly employed because of the wage contract are likely to behave differently from the ones who are voluntarily working. As briefly mentioned above, for example, a rise in involuntary employment contributes to an increase in credit goods since households who are forced to work by the wage contract may increase their consumption to compensate for increased welfare costs from voluntarily working. In this subsection, I discuss the behaviors of this type of households. To this end, let me first define a marginal worker in the economy. Define $V^{E}(\theta, \Theta, \widetilde{W})$ a value function for a employed household under $\widetilde{W} \cdot V^{N}(\theta, \Theta, \widetilde{W})$, $V^{E}\left(\theta, \Theta, W^{c}\right)$, and, $V^{N}\left(\theta, \Theta, W^{c}\right)$ can be defined in a similar way. A household is defined as a marginal worker if

$$
V^{E}(\theta, \Theta, \widetilde{W}) \geq V^{N}(\theta, \Theta, \widetilde{W}) \text { and } V^{E}\left(\theta, \Theta, W^{c}\right)<V^{N}\left(\theta, \Theta, W^{c}\right)
$$

Or

$$
V^{E}(\theta, \Theta, \widetilde{W})<V^{N}(\theta, \Theta, \widetilde{W}) \text { and } V^{E}\left(\theta, \Theta, W^{c}\right) \geq V^{N}\left(\theta, \Theta, W^{c}\right)
$$

Equation 8 or 9 implies that a marginal work does not want to work under the contract wages but should work by the wage contract, or she wants to work under the contract wages but cannot work by the contract. Figure 4 reports the responses of key per capita variables for marginal workers 
and non-marginal workers in response to an unexpected increase in money supply. ${ }^{35}$ As expected, the last column of the figure shows that the population of marginal workers increases due to the wage contract. This implies that the aggregate hours variation is largely driven by a rise in the marginal worker population share. Interestingly, marginal workers tend to consume more in compensation for a rise in welfare costs from working: average consumption for marginal workers increases. Not surprisingly, they also increase savings in terms of money holdings. However, non-marginal workers decrease consumption and saving. This implies that, from the general equilibrium perspective, these behaviors of marginal workers lead to a rise in the price level by increasing demand for money.
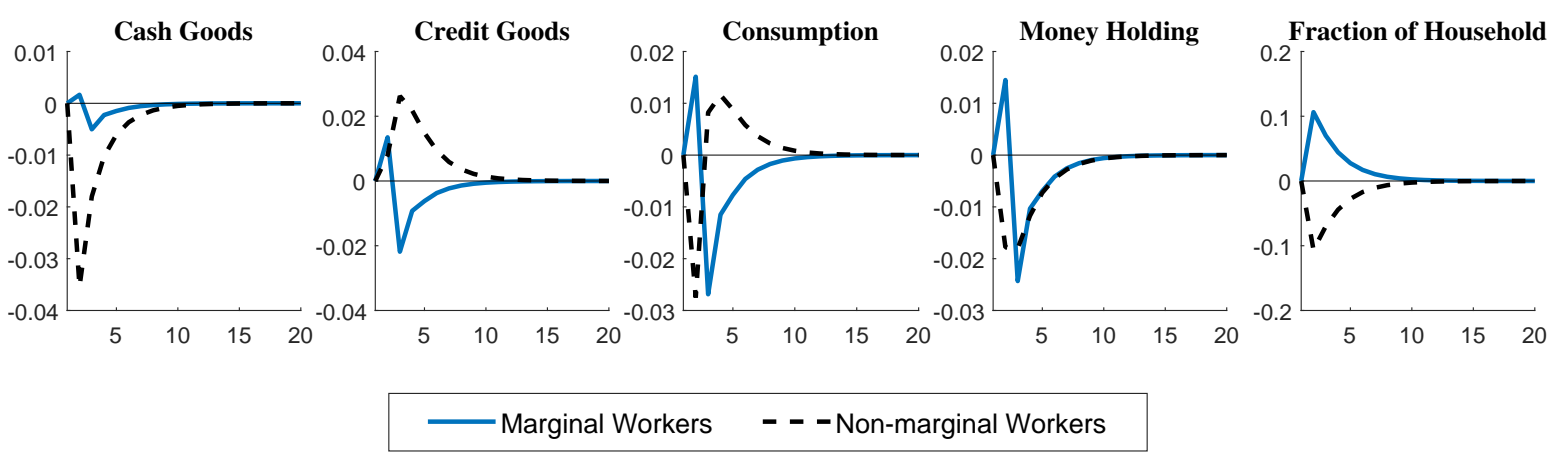

Figure 4: Behaviors of Marginal Workers

Note: The figure shows the responses of key per capita variables for marginal workers and non-marginal workers in response to an unexpected increase in money supply. Marginal workers are defined in Equation 8 and 9. The responses show level changes and the size of responses is normalized by the population share.

To sum up, in response to an unexpected rise in money supply, the population of marginal workers marginal rises, and they tend to increase consumption and savings more than others. This result leads to an important implication for the relation between the effectiveness monetary policy and inequality. Since marginal workers behave differently from other households, a general equilibrium effect depends on the distribution of marginal workers. ${ }^{36}$ An economy with a different level of inequality has a different marginal worker distribution, and therefore the effectiveness monetary policy will be different. I will discuss this issue in detailed in Section 5.

\footnotetext{
${ }^{35}$ The responses show level changes and the size of responses is normalized by the population share.

${ }^{36}$ The distribution of marginal workers affects the population size of these households in the economy and the gap between the values functions, $\left|V^{E}(\theta, \Theta, \widetilde{W})-V^{N}\left(\theta, \Theta, W^{c}\right)\right|$ or $\left|V^{N}(\theta, \Theta, \widetilde{W})-V^{E}\left(\theta, \Theta, W^{c}\right)\right|$.
} 


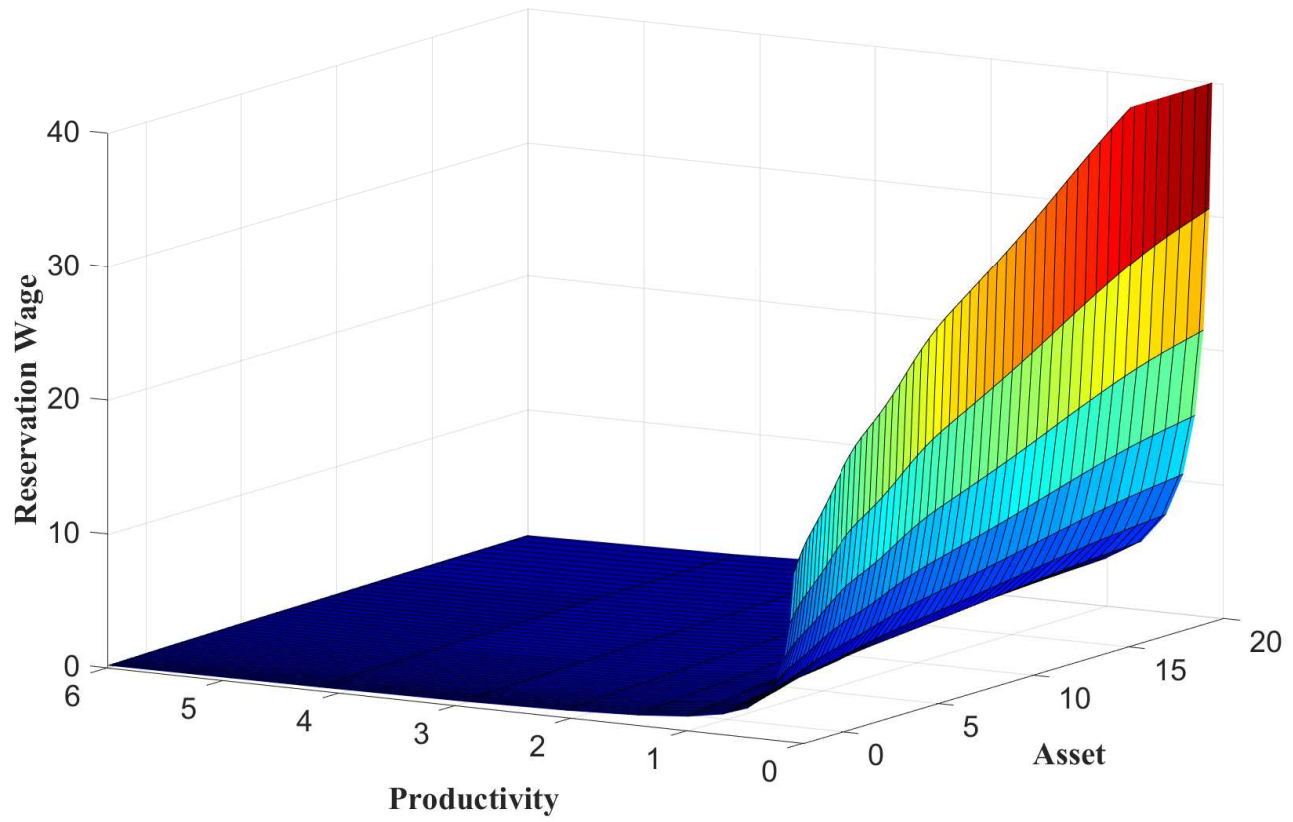

Figure 5: Reservation Wage Rate (per effective labor) Distribution Note: The figure shows the per effective reservation wage distribution over productivity and assets.

\subsection{Distributional Effects of Monetary Policy}

\subsubsection{Reservation Wages Distribution}

It is also useful to discuss the reservation wage distribution generated by the model economy to have better understanding of the employment decisions for households in the model economy, which is one of the key mechanism for monetary policy shocks. Figure 5 shows the reservation wage rate (per effective labor), $W^{R}(\theta, \Theta)$, distribution over labor productivity and net wealth in the model economy. As briefly discussed earlier, the reservation wage rate is different across households types: as expected, it is an increasing function of net asset holdings but is a decreasing function of labor productivity.

From this figure, we can have two implications. First, as discussed in Chang and Kim (2006), the aggregate labor supply responses depend on how different are individual reservation wages compared to the market wage. In other words, a marginal worker distribution can be determined by the reservation wage distribution. Since the shape of reservation wage distribution will depend on productivity 

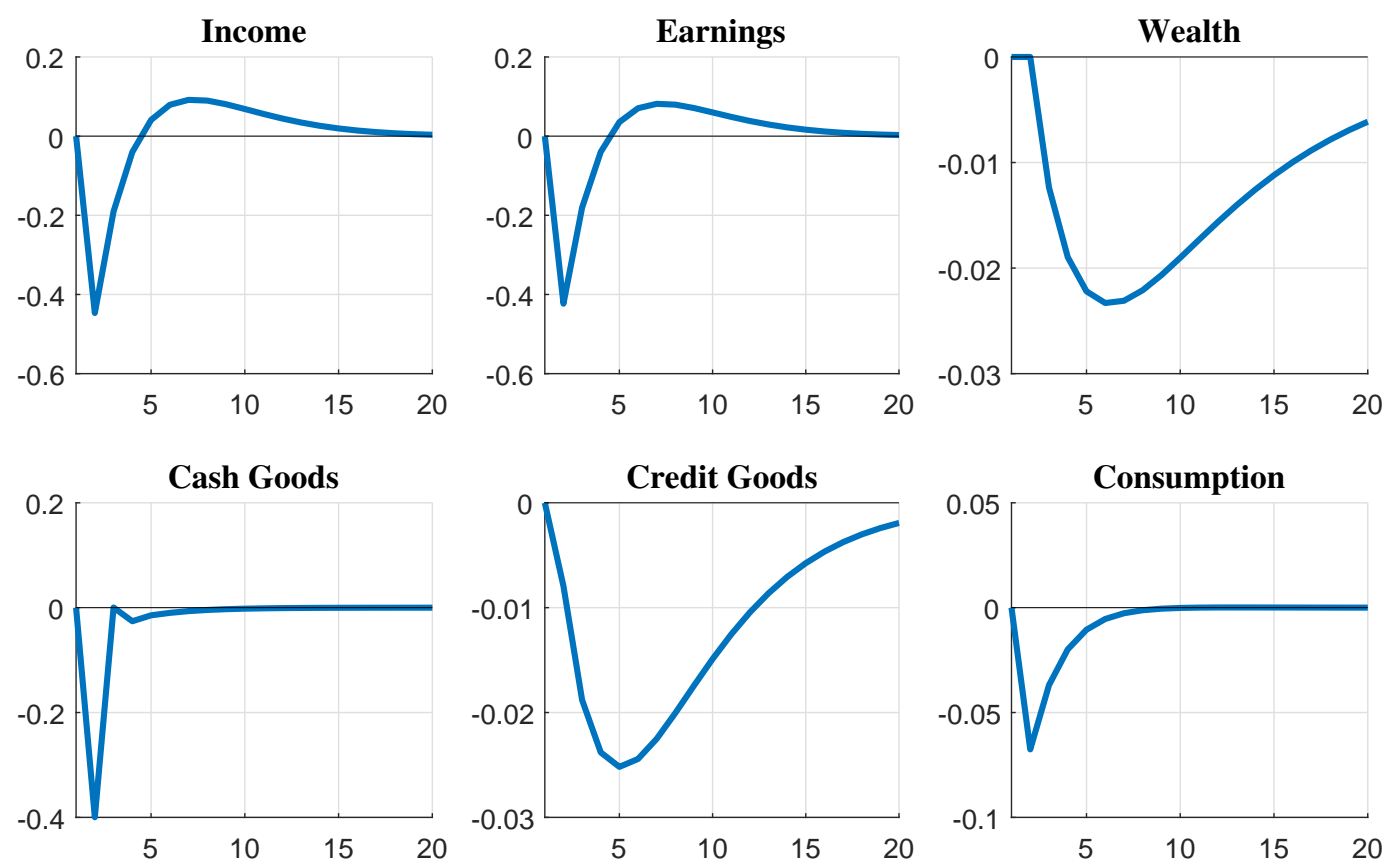

Figure 6: The Effects of Monetary Policy on Gini Coefficients

Note: The figure depicts the effects of one-standard-deviation expansionary monetary policy shocks on Gini coefficients of income, earnings, wealth, and consumption (cash goods, credit goods, and total consumption). The Gini coefficients are logged, so the responses are percentage deviations from the steady state.

and wealth distributions, a marginal worker distribution also will rely on the inequality status of the economy. I will discuss this issue in detail in Section 5.

Second, by assumption, households are employed in an ascending order by their reservation wage rates (per effective labor) until they provide what the firms demand. Hence, households whose reservation wage rates were slightly higher than the contract wage are likely to be newly employed in response to monetary policy shocks. In other words, since the reservation wage is a decreasing function of productivity and an increasing function of assets, employment of households with relatively low productivity or higher wealth will be mostly affected by changes in monetary policy actions. This implies that monetary policy can have substantially different effects on households in the economy, depending on their reservation wages. The distributional effects of monetary policy shocks will be discussed next.

\subsubsection{The Effect of Monetary Policy on Inequality}

One of the main focuses of this study is on the distributional effects of monetary policy shocks. Substantially different reservation wages across households suggest that monetary policy shocks could have 


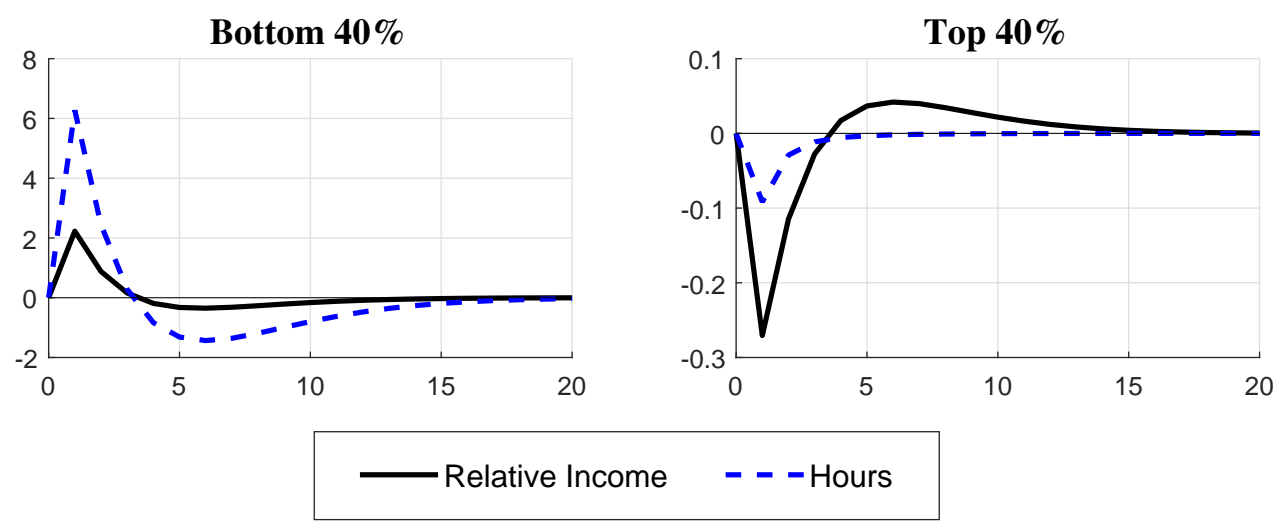

Figure 7: Responses of Relative Income and Hours over Income Note: The figure shows responses of relative income to average and hours between the bottom and the top 40 percent of income.

sizable effects on inequality in the economy. Figure 6 depicts the effects of one-standard-deviation expansionary monetary policy shocks on Gini coefficients of income, earnings, wealth, and consumption (cash goods, credit goods, and total consumption). An expansionary monetary policy shock, indeed, decreases inequality in wealth, earnings, income, and consumption, as is suggested by the empirical literature such as Furceri, Loungani and Zdzienicka (2016) and Coibion et al. (2017). A one-standarddeviation expansionary monetary policy (money growth) shock reduces Gini coefficients of earnings, income, and consumption by $0.57,0.54$, and 0.07 percent, respectively. Since wealth is a state variable, it does not respond immediately, but its inequality decreases slowly after a monetary policy shock: the Gini coefficient of wealth falls by 0.03 percent after 5 quarters of the shock. Overall, the transmission channel through which an unanticipated monetary easing affects inequality in the model economy is through an increase in employment from the bottom of distributions induced by nominal wage contracts. Firms hire more workers after a monetary expansion due to a fall in real wages. As discussed above, newly employed households tend to be less productive. This implies that employment is likely to arise at the bottom of distributions since less productive households tend to belong to the bottom. This generally holds for income, earnings and consumption distributions since labor income is the main source of total income and consumption dynamics is largely affected by changes in income. Regarding the wealth distribution, one may argue that an unexpected increase in money supply would increase wealth inequality since newly employed households may be wealthy in that the reservation wage is also an increasing function of wealth. However, if new workers in the top of wealth distribution have relatively smaller productivity than the newly employed households in the bottom, wealth inequality can decrease after the monetary easing. In this model economy, these two effects indeed coexists, but 
wealth inequality falls as the latter effect dominates.

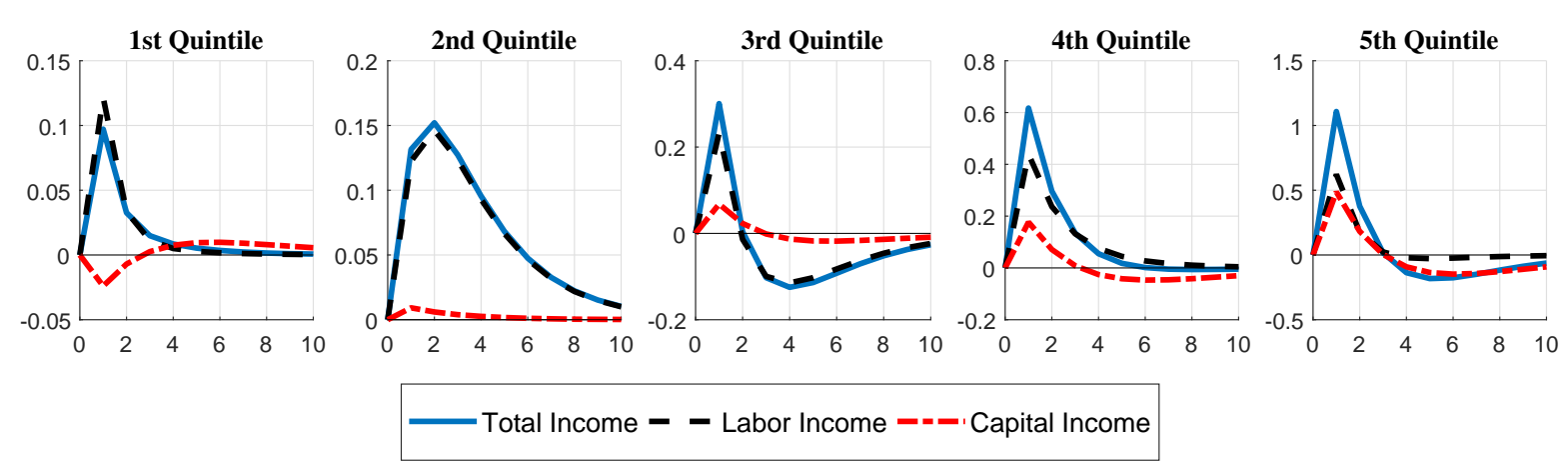

Figure 8: Decomposition of Income Share Responses

Note: The figure shows changes in levels of total income, labor income, and capital income to expansionary monetary policy shocks.

As an example of the distributional effects of monetary policy shocks, I show the responses of relative income to average and hours over the income distribution in Figure 7. As explained above, income-poor households tend to be newly employed in response to an unexpected rise in money supply: hours at the bottom 40 percent increase by 6 percent. The increase in employment from the bottom of the income distribution leads to a fall in income inequality: the relative income for the poor (the bottom 40 percent) increases while the rich (the top 40 percent) lose their income in a relative sense, which makes the income Gini coefficient decrease by around 0.4 percent on impact.

Another interesting implication of the distributional effects of monetary policy is from the different responses of real wages and real asset prices. The former increases employment and in turn labor income while the latter leads to a rise in capital income. Hence, the different responses of factor rental prices result in asymmetric effects on income, depending on how households compose their income. To better understand how the different responses of real wages and real asset prices have compositional impacts, I decompose the responses of the level of income across the wealth distribution into two income sources, labor and capital incomes, in Figure 8 and Table 5. As shown in Figure 8, the increase in total income for the poor is mainly due to a huge rise in labor income which is induced by an increase in employment. For example, as found in Table 5, an increase in income on impact for households in the second wealth group is mostly explained by a rise in labor income: the contribution 
Table 5: Decomposition of Income Responses on Impact

\begin{tabular}{lrrrrr}
\hline \hline & \multicolumn{5}{c}{ Quintile } \\
\cline { 2 - 6 } & 1st & 2nd & 3rd & 4th & 5th \\
\hline \multicolumn{7}{c}{ Level Change } \\
Total Income & 0.10 & 0.13 & 0.30 & 0.62 & 1.11 \\
Labor Income & 0.12 & 0.12 & 0.23 & 0.44 & 0.62 \\
Capital Income & -0.02 & 0.01 & 0.07 & 0.18 & 0.49
\end{tabular}

\section{Contribution Rate (\%)}

\begin{tabular}{lrrrrr} 
Total Income & 100.0 & 100.0 & 100.0 & 100.0 & 100.0 \\
Labor Income & 124.59 & 93.01 & 77.43 & 71.32 & 56.10 \\
Relative to mean & 1.50 & 1.08 & 0.94 & 0.82 & 0.66 \\
Capital Income & -24.59 & 6.99 & 22.57 & 28.68 & 43.90 \\
Relative to mean & -1.86 & 0.53 & 1.37 & 2.04 & 2.92 \\
\hline
\end{tabular}

Note: The upper panel shows a income level change to expansionary monetary policy shocks on impact, and the bottom panel shows contribution rates of each income sources to the total income change.

rate of labor income to the rise in total income is 93 percent while it is only 7 percent for capital income. Relative contribution rates for labor income at the bottom of the wealth distribution is relatively large: it is 1.5 for the poorest wealth group but is only 0.66 at the top. This means that labor income of asset-poor households is relatively important when comparing it to their capital income and to labor income in other asset-rich groups. Interestingly, since an unexpected monetary expansion positively affects the real asset returns, capital income considerably rises for richer households. According to Table 5, the contribution of capital income increases with the level of asset holdings. For example, the contribution rate of capital income to the rise in total income is 44 percent for the top wealth group, which is three times as large as the mean. This implies that a rise in real asset return sharply increases capital income in the upper wealth quintiles. Therefore, there are compositional effects of monetary policy on income across the wealth distribution: the poor benefit from an increase in employment whereas the rich benefit from a rise in the real asset returns in a relative sense.

Importantly, there are asymmetric responses of consumption across the wealth distribution. The upper panel in Figure 9 exhibits the responses of cash goods, credit goods, and total consumption by the wealth quintiles to an unexpected rise in money supply. As far as cash goods are concerned, a rise in the price level hurts asset-rich households in the economy: households in the upper wealth 

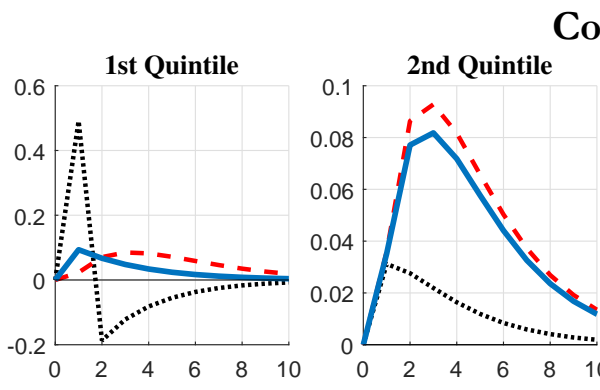

\section{Consumption Responses}
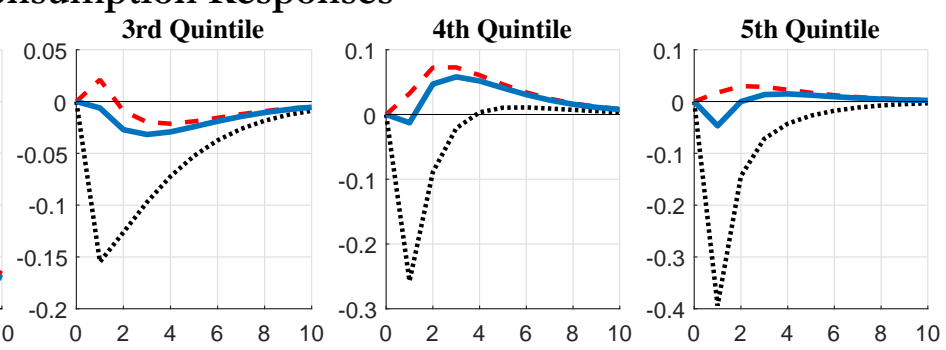

......... Cash Goods - - - Credit Goods _Total Consumption
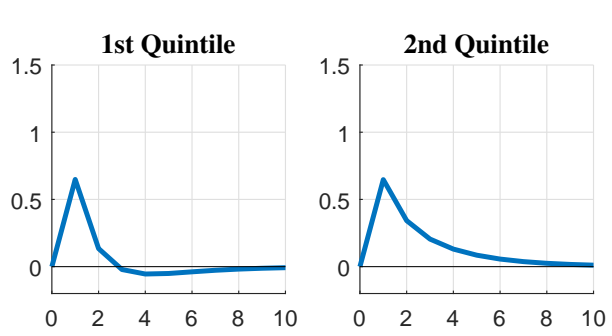

Hours Responses
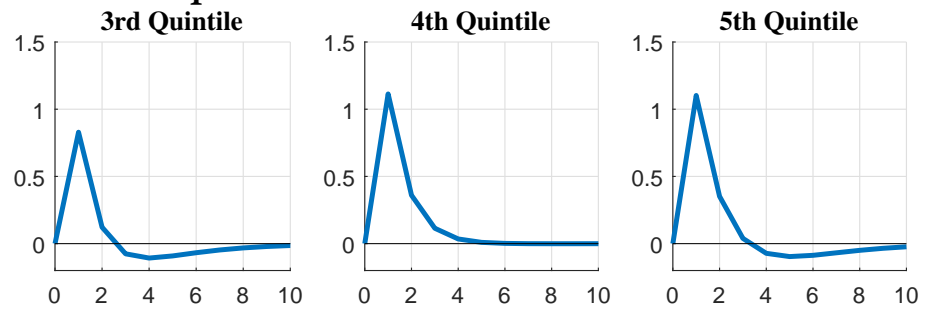

Figure 9: Responses of Consumption and Hours across Wealth Quintiles

Note: The upper panel depicts the responses of cash goods, credit goods, and total consumption to expansionary monetary policy shocks across the wealth quintiles, and the bottom shows the responses of hours across the wealth quintiles.

quintiles (third to fifth wealth groups) reduce cash goods. This is because higher inflation plays a role in a rise in consumption taxes, and in particular, the wealthiest reduce cash goods significantly relative to other households. Households in the first and second wealth groups increase their cash goods since a sudden rise in the money transfer injected by the government dominates the effect caused by price level increase. Since all the wealth quintiles supply more hours to the firms as found in the bottom panel of Figure 9, their labor income rises, ${ }^{37}$ and this rise allows households to increase their credit goods on average. On net, households in the bottom of the wealth distribution increase total consumption (the sum of cash and credit goods) while asset-rich households tend to decrease total consumption. Therefore, inflation hurts wealthy households more. This model result may support the empirical findings in the literature (e.g., Doepke and Schneider (2006)).

\footnotetext{
${ }^{37}$ Of course, a reduction in real wages can decrease labor income to some extents, but a rise in hours may dominate this effect.
} 


\subsection{Empirical Evidence}

I provide empirical evidence for the key mechanism or results in the model economy. I first discuss an empirical analysis on the cyclicality of real wages and real asset prices in response to monetary policy shocks. I then empirically document the heterogeneous responses of consumption and employment.

\subsubsection{Responses of Real Wages and Real Asset Prices}

In the model economy, sluggish adjustment of real wages is central for understanding the monetary transmission mechanism. Also, a rise in real asset returns is important in explaining the effects on assetrich households. To estimate the response of real wages or real asset returns to monetary policy shock, I consider a three-variable Vector Autoregressive (VAR) model, including the measure of monetary policy shocks, ${ }^{38}$ federal funds rates, and real wages or real asset prices. I consider the following reducedform VAR,

$$
Y_{t}=A(L) Y_{t-1}+v_{t}
$$

where $Y_{t}$ is a vector including the monetary policy shock measure, federal funds rates, and logged real wages or real asset prices, $A(L)$ is a polynomial in the lag operator; $v_{t} \sim N(0, \Omega)$ are reducedform innovations. The structural innovations, $\xi_{t} \sim N(0, I)$, are defined by an orthonormal rotation of the reduced-form residuals:

$$
\xi_{t}=B_{0} v_{t}
$$

where $B_{0}^{-1}\left(B_{0}^{-1}\right)^{\prime}=\Omega$. I order the measures for monetary policy shocks first and real wages or real asset prices last in the VAR and identify the matrix $B_{0}^{-1}$ using the Cholesky decomposition of $\Omega$. Constant terms, fourth-degree-polynomial trend terms, and four lags are included in the VAR. As

\footnotetext{
${ }^{38}$ Measures for monetary policy shocks are from Coibion et al. (2017). They update the measure of Romer and Romer (2004) until the fourth quarter of 2008.
} 
discussed in Anderson, Inoue and Rossi (2016), by including the shocks measures in a VAR where the shock is ordered first, we can ensure that the shock is uncorrelated with past information contained in the other variables in the VAR, and other variables response to the shocks contemporaneously. Real wages are defined as average hourly earnings of production and nonsupervisory employees for total private. ${ }^{39}$ Real house price is real residential property prices, and real stock price are defined total share prices for all shares. ${ }^{40}$
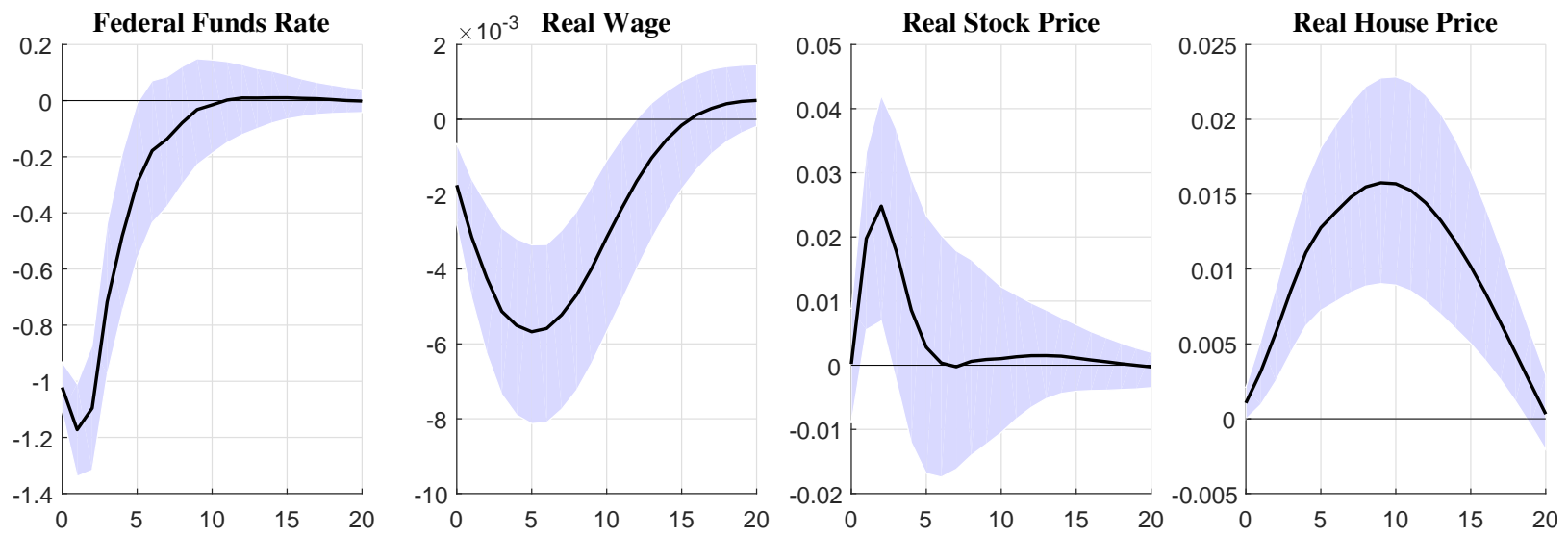

Figure 10: Responses of Real Wage and Real Asset Prices

Note: The figure shows the responses of real wages and real asset prices to an expansionary monetary policy shock. Real wages are defined as average hourly earnings of production and nonsupervisory employees for total private deflated by producer price index for all commodities; real house prices are real residential property prices; real stock prices are defined as total share prices for all shares deflated by price index for all urban consumers for all items.

The responses of real wages and real asset prices to an expansionary monetary policy shock are reported in Figure 10. I first discuss the dynamic behavior of real wages. As expected by the model economy, the real wage drops after a monetary easing as shown in the second column. The real wage rate decreases on impact and has a smallest value in 5 quarters after the shock. This empirical result is inconsistent with that in Christiano, Eichenbaum and Evans (2005), who find that the real wage is mildly procyclical in response to monetary policy shocks. ${ }^{41}$ However, there are also abundant empirical evidence suggesting that real wage is coutercyclical in response to monetary policy shocks. For example, Spencer (1998) provides empirical findings that the real wage response is strongly and robustly negative in response to demand shocks, which supports sticky-wage theories of the business cycle including the

\footnotetext{
${ }^{39}$ It is deflated by producer price index for all commodities

${ }^{40}$ Real stock prices are computed by deflating them by price index for all urban consumers for all items

${ }^{41}$ Gamber and Joutz (1993) also find in general a positive dynamic response of real wages to monetary policy shocks.
} 
model economy in this paper. Similarly, Balmaseda, Dolado and Lopez-Salido (2000) empirically document that real wages are countercyclical in response to aggregate demand shocks. Leiderman (1983) also finds that real wage response to an unanticipated increase in money growth is weakly negative. ${ }^{42}$

As discussed by Kaplan, Moll and Violante (2018), having asset price movements consistent with empirical evidence is potentially important in understanding the transmission mechanism of monetary policy. Werning (2015) also shows that the response of consumption to monetary policy shock depends on the cyclical movement of asset prices. In light of this discussion in the literature, cyclical real asset returns generated in the model economy are well supported by empirical evidence. The third and fourth columns show the responses of real stock prices and real house prices, respectively, to an unanticipated monetary easing. Consistent with the model assumptions, both real asset prices increase with an unexpected monetary expansion. The response of the real house price is smoother that of the real stock price, which suggests that there are more frictions in the housing market. Empirical studies (e.g., Furceri, Loungani and Zdzienicka (2016)) in the literature also find the consistent results.

To sum up, the dynamic behaviors of both the real wages and real asset prices in the model economy are well supported by the empirical results.

\subsubsection{Heterogeneous Responses of Employment}

I also provide supportive empirical evidence for the different responses of employment across income groups to monetary policy shocks, which is the key channel of the model. For this analysis, I use the Current Population Survey (CPS). Since information on income in the CPS is available in March of every year, I cannot use quarterly data for employment rates across income quintiles. Hence, I use annual data spanning 1969 to 2008 . To estimate the effects of monetary policy shocks on employment by income, I employ the VAR where the monetary policy shocks measure are ordered first, and constant terms, quadratic trend terms, and a one-period lag are included. Figure 11 reports the estimated response of employment rates across income groups. As predicted by the model economy, households in the lower income quintiles increase employment while employment rates for richer households tend

\footnotetext{
${ }^{42}$ One possible reason why there is no broad agreement among researchers on the basic empirical facts regarding wage rigidity is that real wages are hard to measure, and it is difficult to know whether observed wages are allocative (Basu and House, 2016). Regarding this issue, Lastrapes (2002) concludes that the reason for the disaggrement is a lack of robustness of the estimated wage response functions to model specification, data transformation to induce stationarity, the choice of proxy for the aggregate real wage, and the choice of variables to include in the VAR.
} 
to decrease in response to expansionary monetary policy shocks.
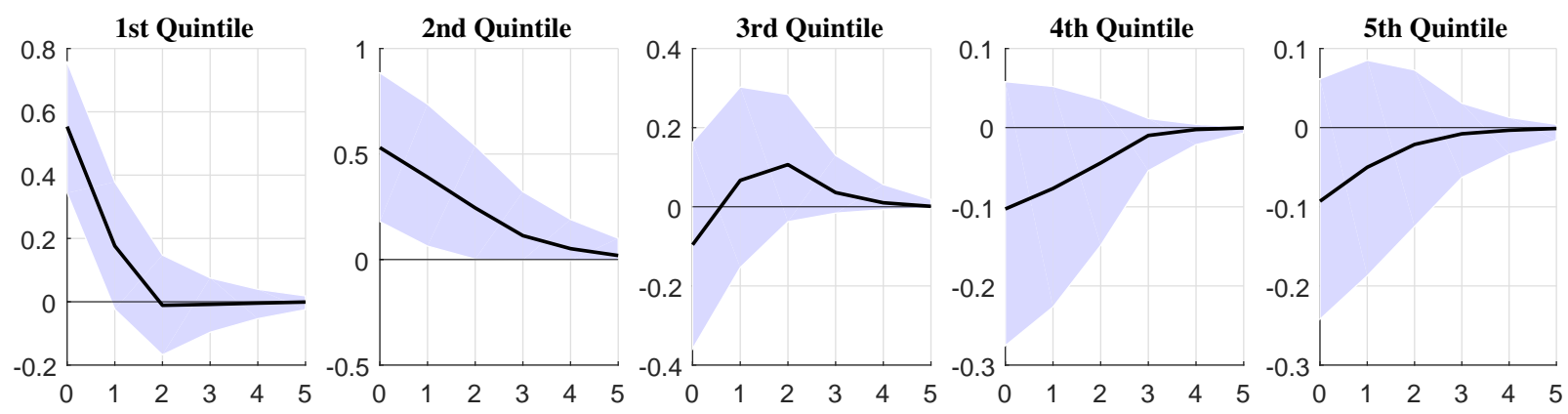

Figure 11: Response of Employment across Income Quintiles Note: The figure presents the responses of employment across different income quintiles to an expansionary monetary policy shock.

\subsubsection{Heterogeneous Responses of Consumption}

I also provide empirical evidence that there are heterogeneous responses of consumption to monetary policy shocks. To this end, I use the Consumer Expenditure Surveys (CEX), which is conducted by the Bureau of Labor Statistics (BLS), to collect information on consumption and age across individual households. ${ }^{43}$ I mainly use quarterly data which span from the first quarter of 1980 to the fourth quarter of 2008. The measure of non-durable consumption includes food and beverages, tobacco, apparel and services, personal care, gasoline, public transportation, household operation, medical care, entertainment, reading material and education. The definition of the non-durable goods is similar to that of Anderson, Inoue and Rossi (2016) and De Giorgi and Gambetti (2012). ${ }^{44}$ Non-durable consumption for households is real per capita values: they are divided by family size (the number of family members), deflated by CPI-U series, and seasonally adjusted by X-12-ARIMA. Since net wealth data are not available not even for every year, I use age dimension as a proxy for asset holdings. The measure of age is defined as the age of a head of each household.

I order the measures for monetary policy shocks first, federal funds rates next, and consumption for each age group last in the VAR. Figure 12 presents the responses of consumption across different

\footnotetext{
${ }^{43}$ The CEX is rotating panel data where individuals are interviewed for four consecutive quarters at most.

${ }^{44}$ Anderson, Inoue and Rossi (2016) define non-durable consumption as expenditures on food, alcoholic beverages, tobacco, utilities, personal care, household operations, public transportation, gas and motor oil, and miscellaneous expense, and De Giorgi and Gambetti (2012) use food (including alcohol and tobacco), heating fuel, public and private transport (including gasoline), and personal care as the non-durable consumption.
} 
age groups to an expansionary monetary policy shock. The model economy predicts that households in the bottom of the wealth distribution increase total consumption while asset-rich households tend to decrease total consumption. As shown in Figure 12, the first age group increases their consumption and older households (the fourth and fifth quintiles) tend to reduce their consumption in response to an expansionary monetary policy shock. Considering that older households are asset-rich while the young cohorts own relatively less amount of wealth, the empirical result regarding the heterogeneous behaviors of consumption across the age distribution is broadly consistent with the model predictions.

This empirical finding is consistent with Doepke and Schneider (2006) and Wong (2018). Doepke and Schneider (2006) quantitatively assess the effects of inflation through changes in the value of nominal assets and find that rich and old households are main losers from inflation. Similarly, Wong (2018) empirically estimates age-specific consumption responses to monetary policy shocks and finds that consumption of younger people is more responsive.
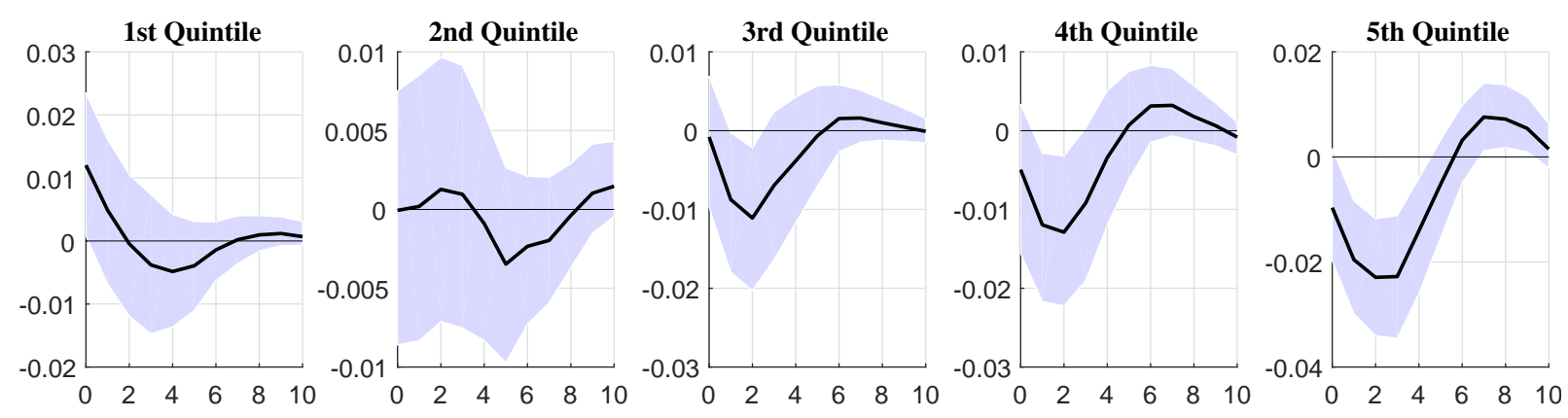

Figure 12: Response of Consumption across Age Quintiles

Note: The figure presents the responses of consumption across different age quintiles to an expansionary monetary policy shock. Consumption is defined as non-durable consumption, and data for consumption are from the CEX 1980:Q1-2008:Q3.

\section{The Impact of Inequality on the Effectiveness of Monetary Policy}

I next turn to the other main contribution of this paper: the role of the long-run level of inequality in the effectiveness of monetary policy. What is the main linkage for the relation? To give a concrete answer to this question, I will take three steps. I first demonstrate the relation between labor supply 
elasticity and the monetary policy effectiveness using the representative-agent model. I then discuss how the long-run level of inequality determines the labor supply elasticity in the model economy where indivisible labor is combined with heterogeneous households. Finally, I integrate the long-run level of inequality and the effectiveness of monetary policy by using labor supply elasticity as the main linkage for the relation.

\subsection{Labor Supply Elasticity and Monetary Policy Effectiveness}

Given the utility function, $\phi$ represents the elasticity of intertemporal substitution of labor supply or Frisch elasticity of labor supply. ${ }^{45}$ Hence, hours worked supplied by households will be more sensitive to changes to wages with a larger value of $\phi$. As discussed by Cho, Cooley and Phaneuf (1997), the parameter $\phi$ also captures the attitude of households toward risk with respect to labor supply: households are less risk averse with respect to hours worked with a high value of $\phi .{ }^{46}$ Since the wage contract generates a higher variation in labor supply, and a degree of risk aversion with regard to labor supply depends on the labor supply elasticity parameter, $\phi$, households behave differently with different values of $\phi$.

Based on the representative-agent models with nominal wage contracts, I demonstrate the relation between labor supply elasticity and the monetary policy effectiveness. The responses of key aggregate variables of two representative-agent economies with different values of $\phi$ to monetary policy shocks are shown in Figure 13. As expected, a degree of risk aversion with regard to labor supply matters for the effectiveness of monetary policy. According to Figure 13, an economy with higher $\phi$ has more effective monetary policy in terms of output. In response to a one-standard-deviation monetary policy (money growth) shock, output increases by 0.15 percent when $\phi=1.14$ while it rises by 0.3 percent in the economy where $\phi=1.5$. The main mechanism of the larger effectiveness of comes from the interplay between a degree of risk aversion with regard to labor supply and the nominal wage contract. Under the wage contract, households must work more than the equilibrium level with an expansionary monetary shocks, which leads to a a decrease in welfare. With a large degree of risk aversion or a small value of $\phi$, households desire to consume more in compensation for an increase in disutility caused

\footnotetext{
${ }^{45}$ The Frish elasticity captures the elasticity of hours worked to the wage rate for a constant marginal utility of wealth. Hence, it measures a pure substitution effect of a wage change.

${ }^{46}$ Cho, Cooley and Phaneuf (1997) find that the welfare cost of nominal wage contract decreases as the value of $\phi$ gets larger.
} 

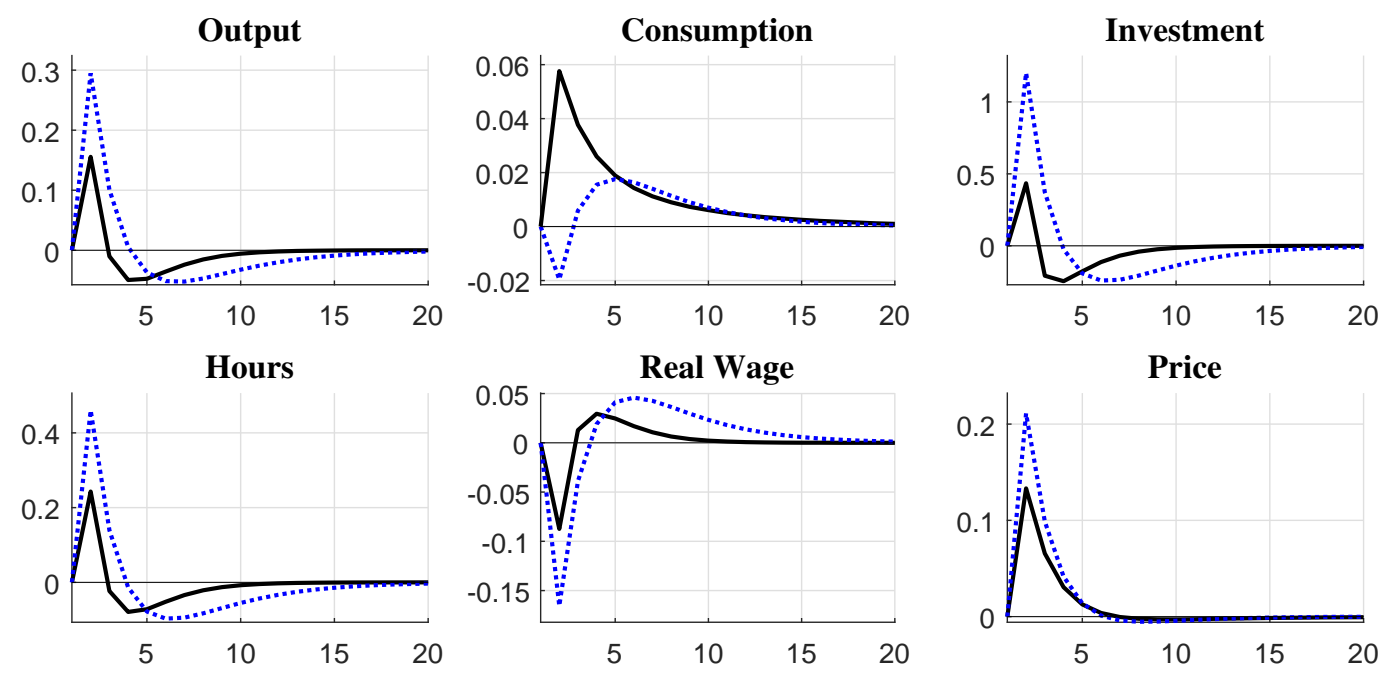

$\phi=1.14 \quad \cdots \cdots \cdots \cdot \ldots=1.50$

Figure 13: Response of Key Variables for Different $\phi$

Note: The figure shows the responses of key aggregate variables of two representative-agent economies with different values of $\phi(\phi=1.14$ and $\phi=1.5)$ to expansionary monetary policy shocks.

by the wage contract, which implies that save less. Since households save by accumulation assets and holding money, demand for money increases by less than in the economy with a smaller degree of risk aversion, which results in a smaller rise in price level. As found in Figure 13, the price increases by 0.13 percent when $\phi=1.14$ while it rises by 0.21 percent when $\phi=1.5$. A rise in price level has the general equilibrium effect: it decreases real wages, and firms hire more workers. This general equilibrium effect is larger in the economy with a smaller degree of risk aversion or a larger value of $\phi$.

\subsection{Inequality and Labor Supply Elasticity}

As found in Chang and Kim (2006) and Rogerson and Wallenius (2009), a degree of heterogeneity in an economy would affect aggregate labor supply elasticity. To be more specific, reservation wages for households can be computed due to the indivisible labor supply assumption in the heterogeneous-agent model. Using the reserve wages across households, the model can endogenously generate different aggregate labor supply curves across the different level of heterogeneity. Intuitively, less heterogeneity is associated with larger aggregate labor supply elasticity. The mass of marginal workers ${ }^{47}$ matters will determine macro labor supply elasticity in the economy. In the more equal economy, there would be

\footnotetext{
47 "A marginal worker" reservation wage is close to the market wage.
} 
more marginal workers, which implies that labor supply elasticity in this society would be relatively

large. In other words, labor supply is more elastic for an economy with a small heterogeneity as the reservation wage distribution is more concentrated.

To investigate the role on heterogeneity in aggregate labor supply elasticity, I consider the model economy with less heterogeneity by decreasing the standard deviation of the idiosyncratic shock process, $\sigma_{x}$, to 0.230 , which is 20 percent less than the benchmark value. In the economy with less heterogeneity, Gini index for income and wealth reduce to 0.53 and 0.65 , respectively, which are 0.59 and 0.68 in the benchmark economy $\left(\sigma_{x}=0.287\right)$. The reservation-wage schedule and invariant distribution allows us to uncover the aggregate labor-supply curve of the economy. Figure 14 reports the inverse cumulative distributions of reservation wages with corresponding participation rates for two different model economies: the economies where $\sigma_{x}=0.287$ and $\sigma_{x}=0.230$. The solid lines represent the benchmark economy $\left(\sigma_{x}=0.287\right)$ while the dotted lines show a counterfactual economy with low inequality $\left(\sigma_{x}=0.230\right)$. Based on these reservation wage schedules, the responsiveness of labor market participation can be computed. I calculate the elasticity at employment rates of 60 percent, which is the steady state employment rate in both economies. For the benchmark economy $\left(\sigma_{x}=0.287\right)$, the elasticity is 1.14 at the steady-state employment rate, while it is 1.5 in the economy with a smaller degree of heterogeneity $\left(\sigma_{x}=0.230\right)$. Hence, a more equal economy has a larger degree of labor supply elasticity, which implies that an economy with less heterogeneity has a less disperse distribution of reservation wages.

\subsection{The Role of Inequality in the Monetary Policy Effectiveness}

Next, I investigate the role of long-run level of inequality in the effectiveness of monetary policy. The main linkage between the long-run level of inequality and the effectiveness of monetary policy is aggregate labor supply elasticity (or the shape of reservation wage distribution). The intuitive explanation is as follows. Suppose that two economies with different heterogeneities have a drop in real wages by the same amount in response to expansionary monetary policy. As discussed earlier, a decrease in real factor prices for labor services allows the firms to hire more workers, and households are employed in ascending order by their reservation wage rates (per effective labor) until they provide the effective labor the firms demand. Since a size of responsiveness of real wages is assumed to be identical, the 


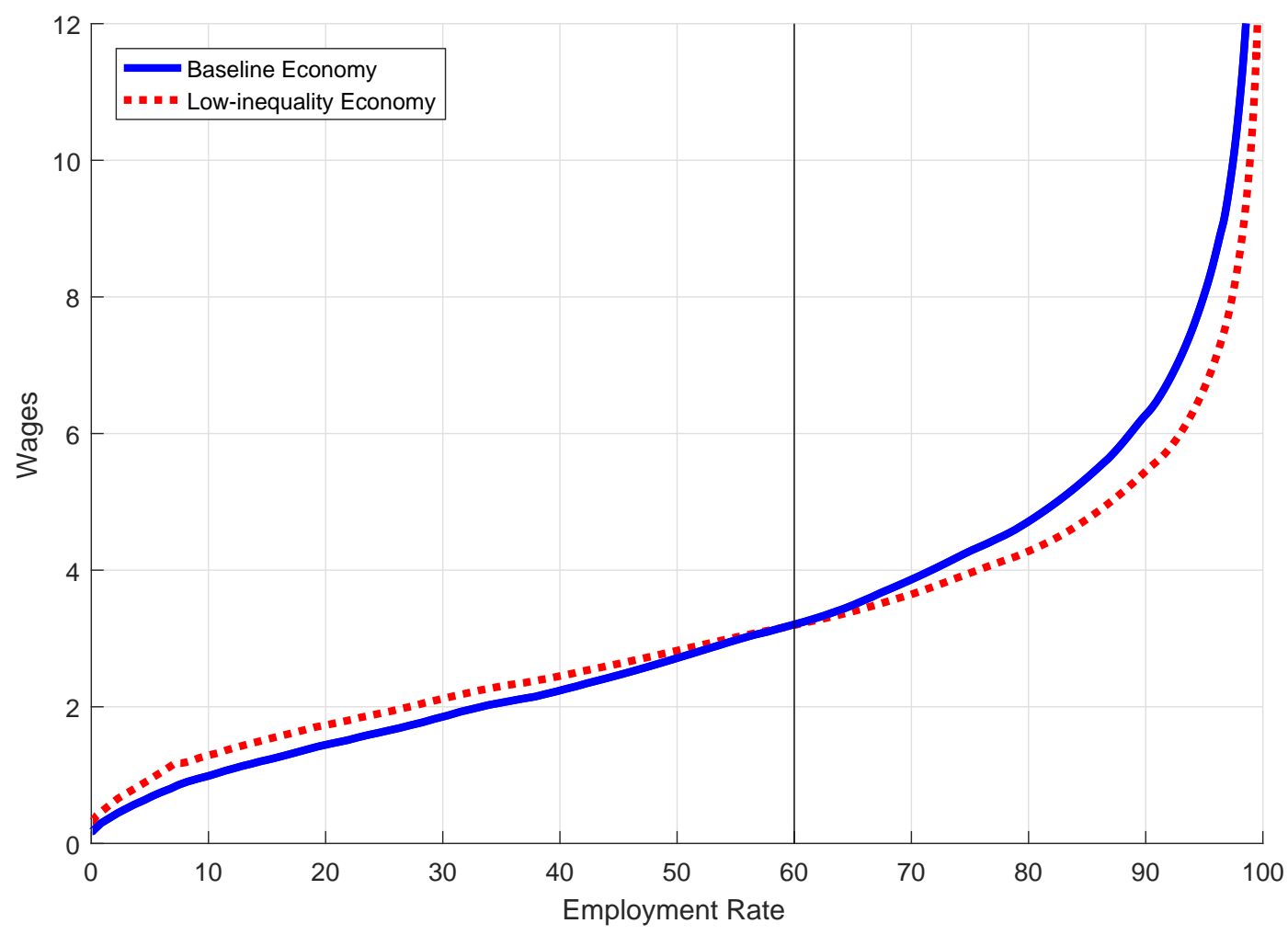

Figure 14: Labor Supply Curves with Different Heterogeneity

Note: The figure shows the inverse cumulative distributions of reservation wages with corresponding participation rates for two different model economies: the economies where $\sigma_{x}=0.287$ and $\sigma_{x}=0.230$. The solid lines represent the benchmark economy $\left(\sigma_{x}=0.287\right)$ while the dotted lines show a counterfactual economy with low inequality $\left(\sigma_{x}=0.230\right)$.

effective labor that the representative firm demands will be the same for the two economies. However, decisions of credit goods will be different in the two economies. Larger labor supply elasticity or a more concentrated reservation wage distribution means that a welfare difference between employment and nonemployment is relatively small, and in turn households tend to increase credit goods by less since disutility from involuntarily working is relatively small. This implies that households in a lowinequality economy increase credit goods by less, and this will lead to a rise in money demand as means of savings. An increase in money demand results in a rise in price and a fall in real wages. Finally, labor demand will rise by more, and this leads output to increase by more in the economy with less heterogeneity.

Figure 15 shows the responses of key aggregate variables of two model economies to monetary policy shocks: the economies where $\sigma_{x}=0.287$ and $\sigma_{x}=0.230$. As expected, the long-run level of inequality matters for the effectiveness of monetary policy. According to Figure 15, a more equal society is associated with more effective monetary policy in terms of output, ceteris paribus. Output 
increases more in the model economy with less heterogeneity that those in the benchmark case: it increases by around 20 percent more than that in the benchmark counterpart. As explained earlier, the main mechanism of the larger effectiveness of comes from the shape of reservation wage distribution, which is represented by the labor supply elasticity. A rise in money demand is larger in the model with less heterogeneity since households in the low-inequality economy reduce their credit goods increase by less due to smaller welfare costs induced by involuntary employment. This generates a larger increase in the price level in the economy as shown in Figure 15. The higher inflation leads to a bigger drop in real rental rate for labor services, and finally it makes the firms to demand larger effective labor with more workers.
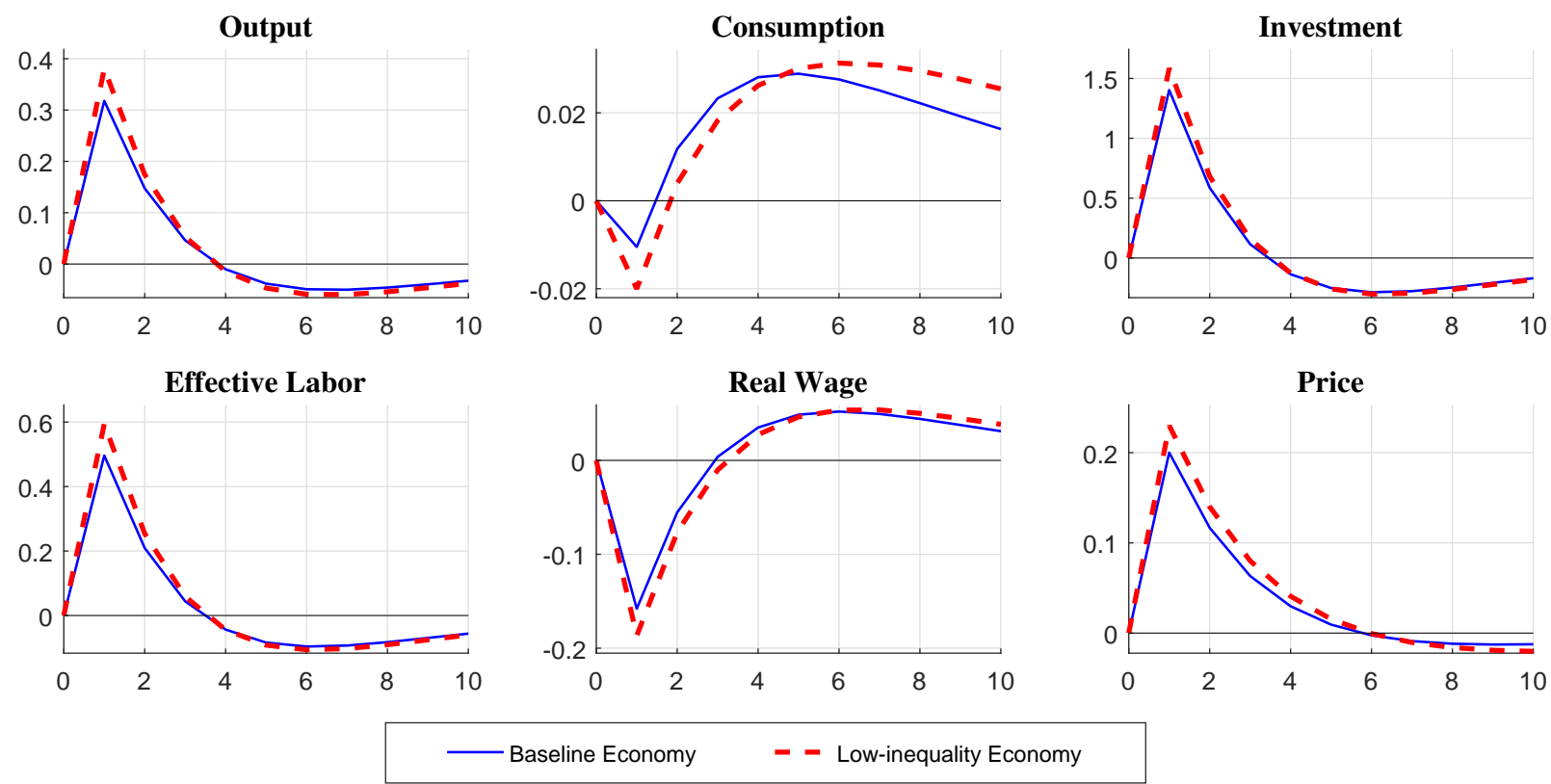

Figure 15: Responses of Key Variables with Different Heterogeneity

Note: The figure shows the responses of key aggregate variables of two model economies to monetary policy shocks: the economies where $\sigma_{x}=0.287$ and $\sigma_{x}=0.230$. The solid lines represent the benchmark economy $\left(\sigma_{x}=0.287\right)$ while the dotted lines show a counterfactual economy with low inequality $\left(\sigma_{x}=0.230\right)$.

To sum up, different heterogeneity in the model economy generates a different level of general equilibrium effects, and it finally affects the effectiveness of monetary policy: a more equal economy has a larger effectiveness of monetary policy in terms of output responses. 


\subsection{Empirical Evidence}

In this section, I provide suggestive empirical evidence for the negative relation between long-run inequality and the monetary policy effectiveness, by using state-level data with national level policy variables.

\subsubsection{Data}

I use state-level data sets for inequality measures in the U.S. but consider national level shocks. By using state-level data with common shocks, I can address two potential problems that would occur in a country-level analysis: one is endogeneity problems due to considerable unobservable heterogeneity across countries, and the other is the normalization issue induced by different sizes of country-level monetary policy shocks. A state-level panel with national shocks in this study helps solve these two issues to some extent since there might be relatively less heterogeneity across states within a country, and common policy shocks are automatically normalized across states since each state faces the identical shocks.

Data on income inequality are taken from Frank (2014), who constructs the inequality measures by state using the pre-tax adjusted gross income published in the Internal Revenue Service (IRS). Frank (2014) computes various measures of income inequality, including the relative mean deviation, Gini coefficient, Atkinson index, Theil's entropy index, as well as the top 1\% and top $10 \%$ income shares. Among them, Gini coefficients are mainly used for this study.

Regarding measures for monetary policy shocks, I use data constructed by Coibion et al. (2017). These measures are a combination of the use of Greenbook forecasts and narrative methods. Using narrative methods, Romer and Romer (2004) compute estimates of variations in intended federal funds rate during Federal Open Market Committee (FOMC) meetings. They then regress the intended federal funds rate on the output and inflation forecasts in the Greenbook at each FOMC meeting date and use the residuals as the monetary policy shocks. Based the method that Romer and Romer (2004) used, Coibion et al. (2017) extend the shock measures until 2008. 


\subsubsection{Estimation I: Two-step Regression}

In order to estimate the impact of the long-run level of inequality on the effectiveness of monetary policy, I employ a two-step approach. In the first step, I consider a three-variable Vector Autoregressive (VAR) model including the monetary policy shock measure, federal fund rates, and GDP for each state and to obtain the effect of monetary policy on output for state $i$, denoted by $\delta_{i}$. The second step is a cross-sectional estimation: I regress $\delta_{i}$ on a measure for inequality which are long-run averages across time for each state, $i$.

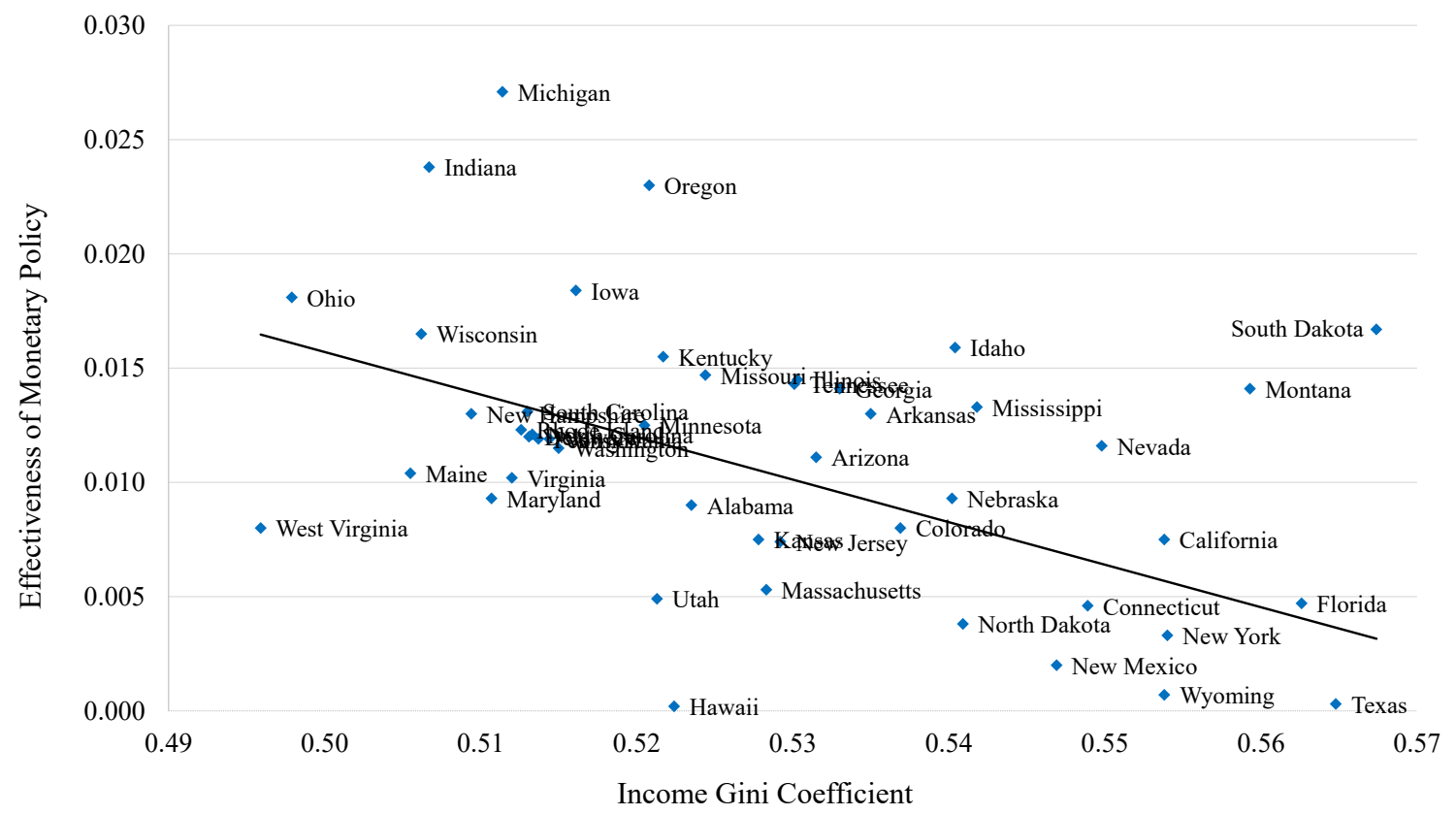

Figure 16: Inequality and the Effectiveness of Monetary Policy I

Note: The figure depicts the relation between the long-run level of inequality and the effectiveness of monetary policy across states, where the effectiveness of monetary policy is measured by the peak output response to expansionary monetary policy shocks, and the long-run level of inequality is defined as the average of historical Gini income coefficients.

Figure 16 shows the relation between the long-run level of inequality and the effectiveness of monetary policy across states, where the effectiveness of monetary policy is measured by the peak output response to expansionary monetary policy shocks, and the long-run level of inequality is defined as the average value of historical Gini income coefficients. As shown in Figure 16, there is a negative relationship between inequality and the effectiveness of monetary policy. The simple correlation between the two variables is -0.5. I regress the effectiveness of monetary policy on the long-run level of inequality. According to Table 6, the slop coefficient is negative and statistically significant: it is -0.18 and is significant at the one percent level. This result is still robust even when I include the long-run 
level of GDP per capita as a control variable following Brinca et al. (2016).

Table 6: Inequality and the Effectiveness of Monetary Policy I

Dependent Variable: Effectiveness of Monetary Policy

(1)

$0.1067^{* * *}$

$(0.0325)$

$-0.1824^{* * *}$

(0.0619)

GDP Per Capita
(2)

$0.2221^{* * *}$

(0.0609)

$-0.1658^{* * *}$

(0.0540)

$-0.0122^{* *}$

(0.0053)

$\begin{array}{lll}\text { Observation } & 50 & 50 \\ \text { R-squared } & 0.23 & 0.34\end{array}$

Note: The table shows the regression results for the relation between the long-run level of inequality and the effectiveness of monetary policy across states, where the effectiveness of monetary policy is measured by the peak output response to expansionary monetary policy shocks, and the long-run level of inequality is defined as the average of historical income Gini coefficients. Values in () are White's robust standard errors. ** and ${ }^{* * *}$ indicate significance at the $5 \%$ and $1 \%$ levels, respectively. Per-capita GDPs are logged values.

\subsubsection{Estimation II: Local Projection Method with Dummy}

As a robustness check, I also use local projection method proposed by Jorda (2005) to estimate impulse response functions (IRFs). ${ }^{48}$ Local projection method has been increasingly used in applied work and can easily be extended to estimate state-dependent effectiveness of economic policies (e.g., Ramey and Zubairy (2014)). To be more specific, the local projection method for panel data simply estimates a series of regressions for each horizon $j$ :

$$
y_{i, t+j}=\alpha_{i, j}+\mathbb{I}_{i, t-1}^{H} \beta_{H, j}\left[\operatorname{Shock}_{t}+\gamma_{H, j} x_{i, t}\right]+\mathbb{I}_{i, t-1}^{L} \beta_{L, j}\left[S h o c k_{t}+\gamma_{L, j} x_{i, t}\right]+\varepsilon_{i, t+j}
$$

where $j=0,2, \ldots, J, y$ is logged GDP, $\alpha$ is state fixed effects which can control for unobserved cross-state heterogeneity, Shock is monetary policy shocks, and $x$ is a vector of control variables. $x$

\footnotetext{
${ }^{48}$ Ramey and Zubairy (2014) use local projection method to estimate impulse responses and government spending multipliers in the U.S., and Furceri, Loungani and Zdzienicka (2016) also study the effect of monetary policy shocks on income inequality using the local projection method with a panel of 32 countries.
} 
includes lagged policy shocks and lagged $y$. IRFs of $y$ at time $t+j$ to the shock at time $t$ can be obtained using the estimated coefficient $\beta_{H, j}$ and $\beta_{L, j} . \mathbb{I}_{i, t-1}^{H}\left(\mathbb{I}_{i, t-1}^{L}\right)$ represents a high(low)-inequality state for each state $i$ at time $t-1$. I use $\mathbb{I}_{i, t-1}^{H}$ in the regression rather than $\mathbb{I}_{i, t}^{H}$ since monetary policy at time $t$ can affect inequality at time $t$. I set $\mathbb{I}_{i, t-1}^{H}\left(\mathbb{I}_{i, t-1}^{L}\right)=1$ when a state $i$ is one of the top (bottom) 10 states among 50 states in terms of the income Gini coefficient at time $t-1$ while $\mathbb{I}_{i, t-1}^{H}\left(\mathbb{I}_{i, t-1}^{L}\right)=0$ otherwise. Hence, $\beta_{H, j}$ is the coefficient associated with the high-inequality states for a horizon $j$ while $\beta_{L, j}$ captures the effects of the shock for low-inequality state for a horizon $j$. Two complications associated with the local projection method in the panel study is (i) covariance structures that vary by a certain characteristic and (ii) the serial correlation in the error terms induced by the successive leading of the dependent variable. In order to address the first issue, I have to use clustered robust standard errors, but the number of clusters is too small. Hence, I decide not to use clustered robust standard errors for the benchmark estimation, but the results with those error are also reported in the appendix and are still robust. For the second issue, I use standard errors with Newey-West correction, which is a standard correction method for the serial correlation problem in the literature.

The estimated responses of GDP to expansionary monetary policy shocks for states of high and low inequality are reported in Figure 17. The results of this exercise show that monetary policy shocks have much larger impacts on output during states of low inequality than high inequality. The effects of monetary policy shocks are negative on impact during states of high inequality, while the on-impact responses are positive when the economy is experiencing low inequality. There are statistically significant differences between the responses of output for high- and low-inequality states in one and two years after the shocks. Hence, the effects of expansionary monetary policy shocks on GDP in the linear estimation model (the thick solid line) are largely driven by low-inequality states. This empirical results provide supportive evidence that a more equal society is associated with more effective monetary policy in terms of output. The empirical finding is broadly consistent with those in the literature on the effectiveness of economic policy and inequality or indebtedness. Yang (2017) investigates the relationship between income inequality and the local government spending multipliers using rich historical state-level data on military procurement and inequality. He finds that the effects of government spending shocks on output are larger in low-inequality states than in high-inequality states. Alpanda and Zubairy (2017) also provide empirical evidence that the effects of monetary policy are less powerful during periods of high household debt. Similarly, Voinea, Lovin and Cojocaru (2018) find that 


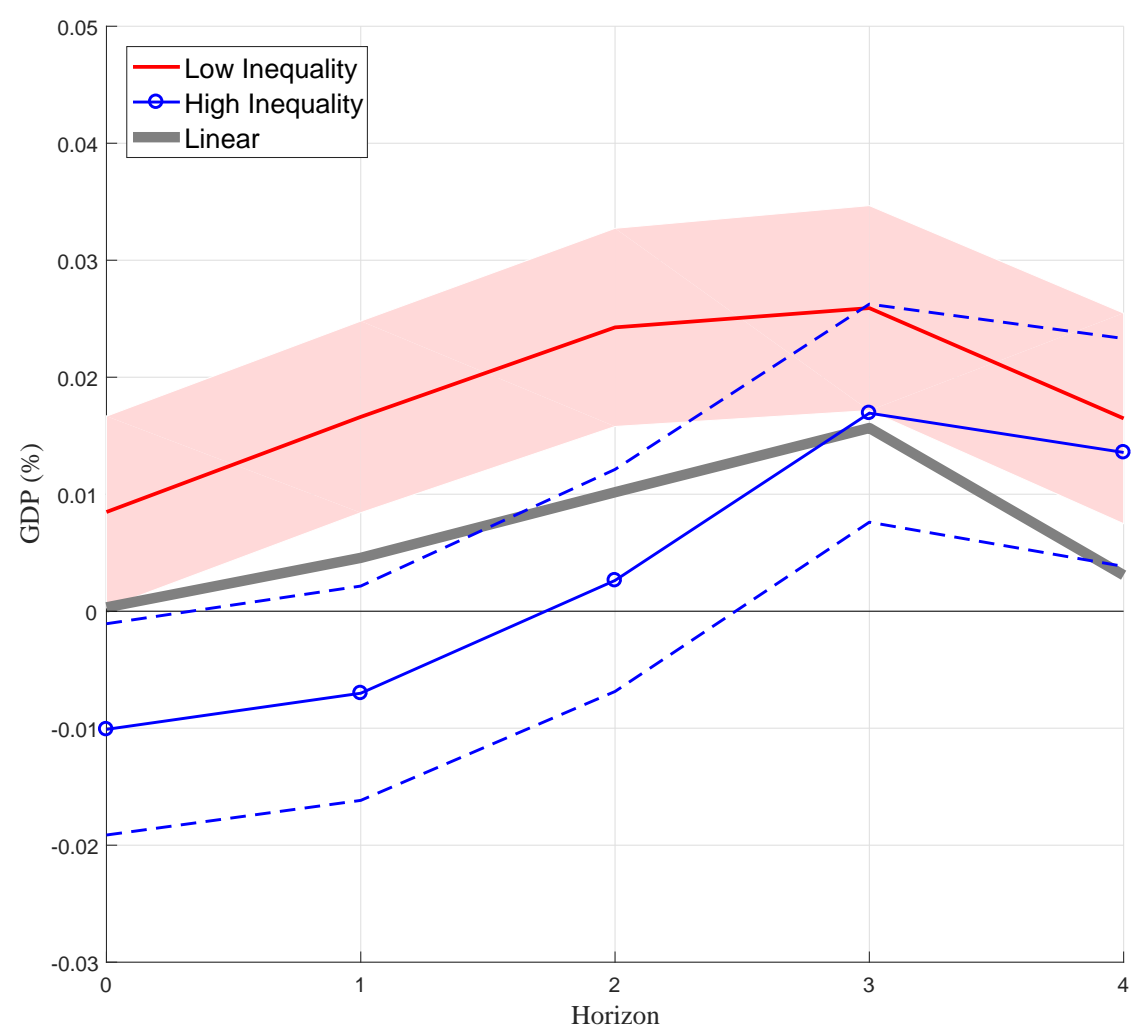

Figure 17: Inequality and the Effectiveness of Monetary Policy II

Note: The red line (the blue line with circles) shows the response of output to an expansionary monetary policy shock for the low (high) inequality states, and the gray thick solid line represents the unconditional response of output in the linear model. Newey-West standard errors are used, and $68 \%$ confidence intervals are shown with shaded area.

lower inequality is associated with stronger effectiveness and higher homogeneity of monetary policy transmission.

\section{Conclusion}

This study investigates the relation between monetary policy and inequality by asking how one affects the other: the effect of monetary policy on inequality and the role of the long-run level of inequality in the effectiveness of monetary policy. To this end, I develop a simple dynamic stochastic general equilibrium (DSGE) model which incorporate nominal wage contracts and cash-in-advance constraints into a heterogeneous agent model economy with indivisible labor. Two main findings emerge: monetary policy affects inequality in the short run, and inequality matters for the effectiveness of monetary policy in the long run.

In regards to the first main finding, an unexpected monetary expansion decrease inequality. An 
expansionary monetary policy shocks leads to a fall in real wages due to the nominal wage contract, and this allows firms to hire more workers. A rise in employment from the bottom of distributions reduces inequality. There are heterogeneous effects of a monetary expansion on income and consumption across wealth distribution. Wealth-richer households benefit from a rise in the real asset returns while households at the bottom of the wealth distribution benefit from an increase in employment in a relative sense. Asset-poor households tend to increase consumption whereas consumption for wealthy households falls, which implies that inflation hurts rich households more.

As far as the second main finding is concerned, a more equal economy tends to have more effective monetary policy. The size of aggregate labor supply elasticity, which depends on a degree of heterogeneity in an economy, affects the responses of prices and real wages to monetary policy shocks. In an economy with less heterogeneity, the effects of monetary policy shocks on price and real wages will be larger, which leads to a bigger response of output. 


\section{References}

Aiyagari, S. Rao. 1994. "Uninsured Idiosyncratic Risk and Aggregate Saving." The Quarterly Journal of Economics. Vol. 109, No. 3, 659-684. 1, 3, 3.1.1, 26

Alpanda, Sami, and Sarah Zubairy. 2017. "Household Debt Overhang and Transmission of Monetary Policy.” Working Paper. 5, 2, 14, 5.4.3

Anderson, Emily, Atsushi Inoue, and Barbara Rossi. 2016. "Heterogeneous Consumers and Fiscal Policy Shocks." Journal of Money, Credit and Banking, 48(8): 1877-1888. 4.6.1, 4.6.3, 44

Auclert, Adrien. 2017. "Monetary Policy and the Redistribution Channel." NBER Working Paper no. 23451. 3, 2

Bagnall, John, David Bounie, Kim P. Huynh, Anneke Kosse, Tobias Schmidt, and Scott Schuh. 2016. "Consumer Cash Usage: A Cross-Country Comparison with Payment Diary Survey Data." International Journal of Central Banking, 12(4): 1 - 61. 3.4.1, 1

Balmaseda, Manuel, Juan J. Dolado, and J. David Lopez-Salido. 2000. “The Dynamic Effects of Shocks to Labour Markets: Evidence from OECD Countries.” Oxford Economic Papers, 52(1): 3-23. $8,4.6 .1$

Basu, Susanto, and Christopher L. House. 2016. "Allocative and Remitted Wages: New Facts and Challenges for Keynesian Models.” National Bureau of Economic Research, Inc NBER Working Papers 22279. 42

Bernanke, Ben. 2015. "Monetary policy and inequality." 1

Brinca, Pedro, Hans A. Holter, Per Krusell, and Laurence Malafry. 2016. "Fiscal multipliers in the 21 st century." Journal of Monetary Economics, 77: 53 - 69. 2, 15, 5.4.2

Bullard, James B. 2014. "Income inequality and monetary policy: a framework with answers to three questions.” Federal Reserve Bank of St. Louis Speech 235. 1

Camera, Gabriele, and YiLi Chien. 2014. "Understanding the Distributional Impact of Long-Run Inflation." Journal of Money, Credit and Banking, 46(6): 1137-1170. 2 
Chang, Yongsung, and Sun-Bin Kim. 2006. "From Individual to Aggregate Labor Supply: A Quantitative Analysis based on a Heterogeneous Agent Macroeconomy." International Economic Review, 47(1): 1-27. 3, 3.4.3, 28, 3, 4.5.1, 5.2

Chang, Yongsung, and Sun-Bin Kim. 2007. "Heterogeneity and Aggregation: Implications for Labor-Market Fluctuations.” American Economic Review, 97(5), 1939-1956. 1, 3, 3.1.1, 3.1.4, 33

Chang, Yongsung, Sun-Bin Kim, and Frank Schorfheide. 2013. 'Labor Market Heterogeneity, Aggregation, and the Policy-(In)variance of DSGE Model Parameters." Journal of the European Economic Association, 11: 193-220. 3.4.3, 1, 29

Cho, Jang-Ok, and Thomas F. Cooley. 1995. "The Business Cycle with Nominal Contracts." Economic Theory, Springer, vol. 6(1), 13-33. 1, 2, 17, 3, 3.1.4, 3.1.4, 31, 4.3

Cho, Jang-Ok, Thomas F. Cooley, and Louis Phaneuf. 1997. "The Welfare Cost of Nominal Wage Contracting." The Review of Economic Studies, 64(3): 465-484. 5.1, 46

Christiano, Lawrence J. 1991. "Modeling the liquidity effect of a money shock." Quarterly Review, , (Win): 3-34. 1, 3.4.4

Christiano, Lawrence J., Martin Eichenbaum, and Charles Evans. 2005. "Nominal Rigidities and the Dynamic Effects of a Shock to Monetary Policy." Journal of Political Economy, 113(1): 1-45. 4.2, 4.6.1

Coibion, Olivier, Yuriy Gorodnichenko, Lorenz Kueng, and John Silvia. 2017. "Innocent Bystanders? Monetary Policy and Inequality." Journal of Monetary Economics, 88: 70 - 89. 3, 2, 4.5.2, 38, 5.4.1, B.1

Cooley, Thomas F, and Gary D Hansen. 1989. “The Inflation Tax in a Real Business Cycle Model.” American Economic Review, 79(4): 733-748. 1, 2, 17, 3, 3.1.1, 19

Cravino, Javier, Ting Lan, and Andrei A. Levchenko. 2018. "Price stickiness along the income distribution and the effects of monetary policy." NBER Working Paper No. 24654. 1, 5, 2 
De Giorgi, Giacomo, and Luca Gambetti. 2012. "The Effects of Government Spending on the Distribution of Consumption.” Barcelona Graduate School of Economics Working Papers 645. 4.6.3, 44

Diaz-Gimenez, Javier, Vincenzo Quadrini, and Jose-Victor Rios-Rull. 1997. "Dimensions of Inequality: Facts on the U.S. Distributions of Earnings, Income, and Wealth.” Federal Reserve Bank of Minneapolis Quarterly Review, 21(2): 3 - 21. 3, 4, B.2

Doepke, Matthias, and Martin Schneider. 2006. "Inflation and the Redistribution of Nominal Wealth.” Journal of Political Economy, 114(6): 1069-1097. 9, 13, 4.5.2, 4.6.3

Floden, Martin. 2000. "Endogenous monetary policy and the business cycle." European Economic Review, 44(8): 1409 - 1429. 2, 17, 3.1.4, 31, 4.3

Floden, Martin, and Jesper Linde. 2001. "Idiosyncratic Risk in the United States and Sweden:Is There a Role for Government Insurance?" Review of Economic Dynamics 4, 406-437. 3.4.3

Frank, Mark W. 2014. “A New State-Level Panel of Annual Inequality Measures over the Period 1916 - 2005." Journal of Business Strategies, 31(1): 241 - 263. 5.4.1, B.3

Furceri, Davide, Prakash Loungani, and Aleksandra Zdzienicka. 2016. "The Effects of Monetary Policy Shocks on Inequality.” International Monetary Fund IMF Working Papers 16/245. 2, 4.5.2, 4.6.1, 48

Gamber, Edward N., and Frederick L. Joutz. 1993. "The Dynamic Effects of Aggregate Demand and Supply Disturbances: Comment." The American Economic Review, 83(5): 1387-1393. 41

Gornemann, Nils, Keith Kuester, and Makoto Nakajima. 2016. "Doves for the Rich, Hawks for the Poor? Distributional Consequences of Monetary Policy.” Board of Governors of the Federal Reserve System (U.S.) International Finance Discussion Papers 1167. 4, 2, 11, 12

Hansen, Gary D. 1985. "Indivisible Labor and the Business Cycle." Journal of Monetary Economics, 16(3): 309-27. 1, 3, 3.1.1

Huggett, Mark. 1993. "The risk-free rate in heterogeneous-agent incomplete-insurance economies." Journal of Economic Dynamics and Control, Elsevier, vol. 17(5-6), 953-969. 1, 3, 3.1 .1 
Janko, Zuzana. 2007. “Nominal Wage Contracts And The Monetary Transmission Mechanism.” Economic Inquiry, 45(1): 121-130. 3.1.4

Janko, Zuzana. 2008. “Nominal wage contracts, labor adjustment costs and the business cycle.” Review of Economic Dynamics, 11(2): 434 - 448. 1, 2, 17, 3, 3.1.4, 1, 30, 4.3

Jorda, Oscar. 2005. "Estimation and Inference of Impulse Responses by Local Projections." American Economic Review, 95(1): 161-182. 5.4.3

Kaplan, Greg, Benjamin Moll, and Giovanni L. Violante. 2018. "Monetary Policy According to HANK.” American Economic Review 108(3), 697-743. Working Papers 1602. 4, 2, 11, 12, 4.6.1

Kim, Seongeun. 2017. “Quality, Price Stickiness, and Monetary Policy.” Working Paper. 1, 5, 2

Krueger, D., K. Mitman, and F. Perri. 2016. "Chapter 11 - Macroeconomics and Household Heterogeneity." In . Vol. 2 of Handbook of Macroeconomics, , ed. John B. Taylor and Harald Uhlig, 843 921. Elsevier. 2, 16

Krusell, Per, and Anthony A. Smith. 1998. "Income and Wealth Heterogeneity in the Macroeconomy." Journal of Political Economy, 106(5): 867-96. 21, A.2

Lastrapes, William D. 2002. "Real wages and aggregate demand shocks: contradictory evidence from VARs." Journal of Economics and Business, 54(4): 389 - 413. 42

Leiderman, Leonardo. 1983. "The response of real wages to unanticipated money growth.” Journal of Monetary Economics, 11(1): 73 - 88. 8, 4.6.1

Mersch, Yves. 2014. "Monetary policy and economic inequality." 1

Nakamura, Emi, and Jon Steinsson. 2014. "Fiscal Stimulus in a Monetary Union: Evidence from US Regions." American Economic Review, 104(3): 753-92. B.3

Piketty, Thomas. 2014. Capital in the Twenty-First Century. Belknap Press. 1

Ragot, Xavier. 2014. "The case for a financial approach to money demand.” Journal of Monetary Economics, 62: $94-107.2$ 
Ramey, Valerie A., and Sarah Zubairy. 2014. "Government Spending Multipliers in Good Times and in Bad: Evidence from U.S. Historical Data." Journal of Political Economy, forthcoming. 5.4.3, 48

Rogerson, Richard. 1988. "Indivisible Labor, Lotteries and Equilibrium.” Journal of Monetary Economics, 21(1): 3-16. 1, 3, 3.1.1

Rogerson, Richard, and Johanna Wallenius. 2009. "Micro and macro elasticities in a life cycle model with taxes." Journal of Economic Theory, 144(6): 2277 - 2292. Dynamic General Equilibrium. 5.2

Romer, Christina D., and David H. Romer. 2004. “A New Measure of Monetary Shocks: Derivation and Implications.” American Economic Review, 94(4): 1055-1084. 38, 5.4.1, B.1

Smets, Frank, and Raf Wouters. 2003. "An Estimated Dynamic Stochastic General Equilibrium Model of the Euro Area." Journal of the European Economic Association, 1(5): 1123-1175. 1, 3.4.4

Spencer, David E. 1998. “THE RELATIVE STICKINESS OF WAGES AND PRICES.” Economic Inquiry, 36(1): 120-137. 8, 4.6.1

Sterk, Vincent, and Silvana Tenreyro. 2018. "The transmission of monetary policy through redistributions and durable purchases." Journal of Monetary Economics. 18

Tauchen, George. 1986. "Finite state markov-chain approximations to univariate and vector autoregressions." Economics Letters, 20(2): 177 - 181. 3.4.3, 3.4.4, A.1, 51

Voinea, L., H. Lovin, and A. Cojocaru. 2018. "The impact of inequality on the transmission of monetary policy.” Journal of International Money and Finance, 85: 236 - 250. 5, 2, 14, 5.4 .3

Werning, Ivan. 2015. "Incomplete Markets and Aggregate Demand.” NBER Working Paper No. 21448. $10,2,16,4.6 .1$

White House. 2017. "Economic Report of the President." Council of Economic Advisers. 1

Wong, Arlene. 2018. "Transmission of Monetary Policy to Consumption and Population Aging." Working Paper. 9, 4.6.3

Yang, Choongryul. 2017. "Income Inequality and Government Spending Multipliers." Working Paper. $2,15,5.4 .3$ 


\section{Appendix}

\section{A The Computational Algorithm}

\section{A.1 Steady-state (Stationary) Economy}

I summarize the computational algorithm used for the steady-state economy, which means that I find the stationary measure, $\mu_{s s}$. The steps are as follows. ${ }^{49}$

Step 1. Have guesses for endogenous parameters such as $\beta$, $\chi$, and $P$.

Step 2. Construct grids for individual state variables, such as asset holdings, $a$, money holdings, $m$, and logged individual labor productivity, $\hat{x}=\ln x$, where the number of grids for $a, m$, and $\widehat{x}$ are denoted by $n_{a}, n_{m}$, and $n_{x}$, respectively. I choose $n_{a}=35, n_{a}=25$, and $n_{x}=15$. The range of $a$ is $[-3,200]$, and the range of $m$ is $[0.04,5]$. More asset and money grid points are assigned on the lower range using a convex function. $\widehat{x}$ is equally spaced in the range of $\left[-3 \sigma_{\hat{x}}, 3 \sigma_{\hat{x}}\right]$, where $\sigma_{\hat{x}}=\sigma_{x} / \sqrt{1-\rho_{x}^{2}}$.

Step 3. Approximate the transition probability matrices for individual labor productivity, $\mathbb{P}_{x}$, using Tauchen (1986).

Step 4. Solve the individual value functions at each grid point. In this step, I obtain the optimal decision rules for saving $a^{\prime}(a, m, x)$, money holding $m^{\prime}(a, m, x)$, and hours worked $h(a, m, x)$, the value functions $V^{E}(a, m, x), V^{N}(a, m, x)$, and $V(a, m, x)$. The detailed steps are as follows:

(a) Compute the real wage rate in the steady state, $w_{s s}$, through the firm's first-order condition, $w_{s s}=(1-\alpha)\left(\frac{\alpha}{r_{s s}+\delta}\right)^{\frac{\alpha}{1-\alpha}}$, where the steady-state real interest rate, $r_{s s}$, is chosen to be 0.01 .

(b) Make an initial guess for the value function, $V_{0}(a, m, x)$ for all grid points.

(c) Solve the consumption-saving problem for each employment status:

$$
V_{1}^{E}(a, m, x)=\max _{a^{\prime} \geq-3, m^{\prime} \geq 0.04}\left\{\log \left(w_{s s} x \bar{h}+\left(1+r_{s s}\right) a-a^{\prime}-m^{\prime}\right)\right.
$$

\footnotetext{
${ }^{49}$ Individual money holding, $m$, and aggregate price $P$ are divided by aggregate money stock to make them stationary.
} 


$$
\left.-\chi \frac{\bar{h}^{1+1 / \phi}}{1+1 / \phi}+\beta \sum_{x^{\prime}=1}^{n_{x}} \mathbb{P}_{x}\left(x^{\prime} \mid x\right) V_{0}\left(a^{\prime}, m^{\prime}, x^{\prime}\right)\right\}
$$

and

$$
\begin{gathered}
V_{1}^{N}(a, m, x)= \\
\left.\max _{a^{\prime} \geq-3, m^{\prime} \geq 0.04}\left\{\log \left(\left(1+r_{s s}\right) a-a^{\prime}-m^{\prime}\right)+\beta \sum_{x^{\prime}=1}^{n_{x}} \mathbb{P}_{x}\left(x^{\prime} \mid x\right) V_{0}\left(a^{\prime}, m^{\prime}, x^{\prime}\right)\right\}\right\} .
\end{gathered}
$$

(d) Compute $V_{1}(a, m, x)$ as $V_{1}(a, m, x)=\max \left\{V_{1}^{E}(a, m, x), V_{1}^{N}(a, m, x)\right\}$.

(e) If $V_{0}$ and $V_{1}$ are close enough for each grid point, and go to the next step. Otherwise, update the value functions $\left(V_{0}=V_{1}\right)$, and go back to (c).

Step 5. Obtain the time-invariant measure, $\mu_{s s}$ with finer grid points for assets and money holding. Using cubic spline interpolation, compute the optimal decision rules for asset holdings with the new grid points. $\mu_{s s}$ can be computed using the new optimal decision rules and $\mathbb{P}_{x}$.

Step 6. Compute aggregate variables using $\mu_{s s}$. If the computed rental price for capital, the employment rate, and the price level become sufficiently close to the targeted ones, then the steady-state economy is found. Otherwise, reset the endogenous parameters, and go back to Step 4.

\section{A.2 Dynamic Economy}

I summarize the computational algorithm used for the dynamic model economy. In order to solve the dynamic economy, the distribution across households, $\mu$, which affects prices, should be tracked. Instead, I use the first moment of the distribution and the forecasting function for it to solve a dynamic economy following Krusell and Smith (1998).

Step 1. I construct grids for aggregate state variables such as money supply shock, the aggregate capital, and the nominal contract wages in the previous period, and individual state variables such as the individual labor productivity, asset holdings, and money holdings. For the aggregate capital, $K$, and the nominal contract wage in the previous period, $W_{-1}^{c}$, I construct five grid points for both of them. For the logged money supply shock, $\widehat{g} \equiv \log g$, I construct five grid points in the range of $\left[-3 \sigma_{\widehat{g}}, 3 \sigma_{\widehat{g}}\right]$, where $\sigma_{\widehat{g}}=\sigma_{g} / \sqrt{1-\rho_{g}^{2}}$. The grid points for $K, W_{-1}^{c}$, and $\widehat{g}$ are equally spaced. The grids for individual state variables are the same as those in the steady-state (stationary) economy. 
Step 2. I obtain the coefficients of Equation 4 from the market clearing economy. Then I compute the current nominal contract wage using Equation 3 and Equation 4 with the coefficients.

Step 3. I parameterize the forecasting function for the future aggregate capital, $K^{\prime}$, wages for the employment decision, $\widetilde{W}$, and the price level, $P$, such that:

$$
\begin{aligned}
& \log K^{\prime}=a_{0}+a_{1} \log K+a_{2} \log g+a_{3} \log W_{-1}^{c} \\
& \log \widetilde{W}=b_{0}+b_{1} \log K+b_{2} \log g+b_{3} \log W_{-1}^{c} \\
& \log P=c_{0}+c_{1} \log K+c_{2} \log g+c_{3} \log W_{-1}^{c}
\end{aligned}
$$

Step 4. Given the forecasting functions, and the contract wage, $W^{c}$, I solve the optimization problems for the individual households. ${ }^{50}$ This step are as follows:

(a) Employment decision: given the forecasting functions and the contract wage, I solve the optimization problems for individual households and obtain the employment decision rule, $h\left(a, m, x, K, g, W_{-1}^{c}\right) .^{51}$

(b) Consumption-saving decision:given the forecasting functions, the contract wage, and the employment decision rule, $h\left(a, m, x, K, g, W_{-1}^{c}\right)$, I solve the optimization problems for individual households and obtain the policy functions for cash goods $c_{1}\left(a, m, x, K, g, W_{-1}^{c}\right)$, credit goods $c_{2}\left(a, m, x, K, g, W_{-1}^{c}\right)$, asset holdings $a^{\prime}\left(a, m, x, K, g, W_{-1}^{c}\right)$, money holdings $m^{\prime}\left(a, m, x, K, g, W_{-1}^{c}\right)$, and value functions $V\left(a, m, x, K, g, W_{-1}^{c}\right)$.

Step 5. I generate simulated data for 2,500 periods using the value functions for individuals obtained in Step 4. The details are as follows.

(a) I set the initial conditions for $K, g, W_{-1}^{c}$, and $\mu(a, m, x)$.

(b) Given the aggregate state variables, I compute the current nominal contract wage using Equation 3 and Equation 4 with the coefficients.

\footnotetext{
${ }^{50}$ Given the contract wage and price, the real interest rate $r$ can be computed from the firm's profit maximization.

${ }^{51}$ As discussed earlier, the transition probabilities for $x$ and $g$ are approximated using Tauchen (1986).
} 
(c) Obtain $\hat{\widehat{W}}$ : Given the aggregate state variables, the forecasting functions for $K^{\prime}$ and $P$, the contract wage, the evaluated value function obtained in Step 4 (b), $V(a, m, x)$, and $\hat{\bar{W}}$ as a guess for $\widetilde{W}$, I obtain the employment decision rule, $h(a, m, x)$, for households and check if the households provide the effective labor demanded by the representative firm under $\hat{\tilde{w}}=\widetilde{W} / P: L^{c} \equiv((1-\theta) / \hat{\widetilde{w}})^{1 / \theta} K=\int x h(a, m, x) d \mu$. If not, reset $\hat{\widetilde{W}}$.

(d) Obtain $\hat{P}$ : Given the aggregate state variables, the forecasting functions $K^{\prime}$ and $\widetilde{W}$, and the contract wage, the evaluated value function obtained in Step 4 (b), $V(a, m, x)$, and $\hat{P}$ as a guess for $P$, I obtain the decision rules and check if a money market clears under $\hat{P}$ : $1=\int m^{\prime}(a, m, x) x d \mu$. If not, reset $\hat{P}$.

(e) Employment decision: given the aggregate state variables, the forecasting functions for $K^{\prime}$, the contract wage, the evaluated value function obtained in Step 4 (b), $V(a, m, x), \hat{\widehat{W}}$, and $\hat{P}$, I obtain the employment decision rule, $h(a, m, x)$, for households.

(f) Consumption-saving decision: given the aggregate state variables, the forecasting functions for $K^{\prime}$, the contract wage, the evaluated value function obtained in Step 4 (b), $V(a, m, x), \hat{\bar{W}}, \hat{P}$, and, the employment decision rule, $h(a, m, x)$, I obtain the decision rules for $c_{1}(a, m, x), c_{2}(a, m, x), m^{\prime}(a, m, x)$ and $a^{\prime}(a, x)$ for households.

(g) I compute macro variables using $\mu$ : $C_{1}=\int c_{1}(a, m, x) d \mu, C_{2}=\int c_{2}(a, m, x) d \mu, L^{c}=$ $\int x h(a, m, x) d \mu, K^{\prime}=\int a^{\prime}(a, m, x) d \mu, H=\int h(a, m, x) d \mu, Y=K^{\alpha} L^{c(1-\alpha)}$, and $I=Y-C_{1}-C_{2}$.

(h) Obtain the next period measure $\mu^{\prime}(a, m, x)$ using $a^{\prime}(a, m, x), m^{\prime}(a, m, x)$, and transition probabilities for $x$.

Step 6. I obtain the new coefficients for the forecasting functions by the OLS estimation using the simulated time series. ${ }^{52}$ If the new coefficients are close enough to the previous ones, the simulation is done. Otherwise, I update the coefficients, and go to Step 4.

Step 7. I check the goodness of fit for the forecasting functions using $R^{2}$. The high accuracy is obtained.

\footnotetext{
${ }^{52}$ I drop the first 500 periods to eliminate the impact of the arbitrary choice of initial aggregate state variables.
} 


\section{B Data Sources}

\section{B.1 Aggregate Data}

- Federal Fund Rate: Federal fund rate are from the FRED (ID: FEDFUNDS).

- Real Wages: Real wages are defined as real hourly earnings. Nominal hourly earings from the FRED: Average Hourly Earnings of Production and Nonsupervisory Employees for Total Private (ID: AHETPI ), and nominal values are deflated by Producer Price Index for All Commodities (ID: PPIACO).

- Real House Price: Real Residential Property Prices (ID: FEDFUNDS).

- Real Stock Price: Real stock prices are defined as nominal stock price deflated by CPI. Nominal stock prices are from FRED: Total Share Prices for All Shares (ID: QUSR628BIS ). CPI index is also from the FRED: Consumer Price Index for All Urban Consumers for All Items (ID: CPIAUCSL).

- Measures for Monetary Policy Shocks: Measures for monetary policy shocks are from Coibion et al. (2017). They update the measure of Romer and Romer (2004) until the fourth quarter of 2008.

\section{B.2 Micro-level Data}

- Income and Wealth Distributions: Data for income and wealth distributions are from DiazGimenez, Quadrini and Rios-Rull (1997). Diaz-Gimenez, Quadrini and Rios-Rull (1997) summarize statistics regarding wealth, income and earning inequalities using the Survey of Consumer Finance (SCF) 1992.

- Consumption Distribution: Information for consumption distribution is from the Consumer Expenditure Surveys (CEX). I mainly use quarterly data which span from the first quarter of 1980 to the fourth quarter of 2008. The measure of non-durable consumption includes food and beverages, tobacco, apparel and services, personal care, gasoline, public transportation, 
household operation, medical care, entertainment, reading material and education. Non-durable consumption for households is real per capita values: they are divided by family size (the number of family members), deflated by CPI-U series, and seasonally adjusted by X-12-ARIMA.

\section{B.3 State-level Data}

- Income Inequality: Data on state-level income inequalities are taken from Frank (2014). Frank (2014) constructs the inequality measures by state using the pre-tax adjusted gross income published in the Internal Revenue Service (IRS). Frank (2014) computes various measures of income inequality, including the relative mean deviation, Gini coefficient, Atkinson index, Theil's entropy index, as well as the top $1 \%$ and top $10 \%$ income shares.

- Real GDP: Data for state-level nominal GDPs are from Nakamura and Steinsson (2014). Statelevel real GDPs are computed by deflating them using the national GDP deflator.

\section{Additional Tables and Figures}
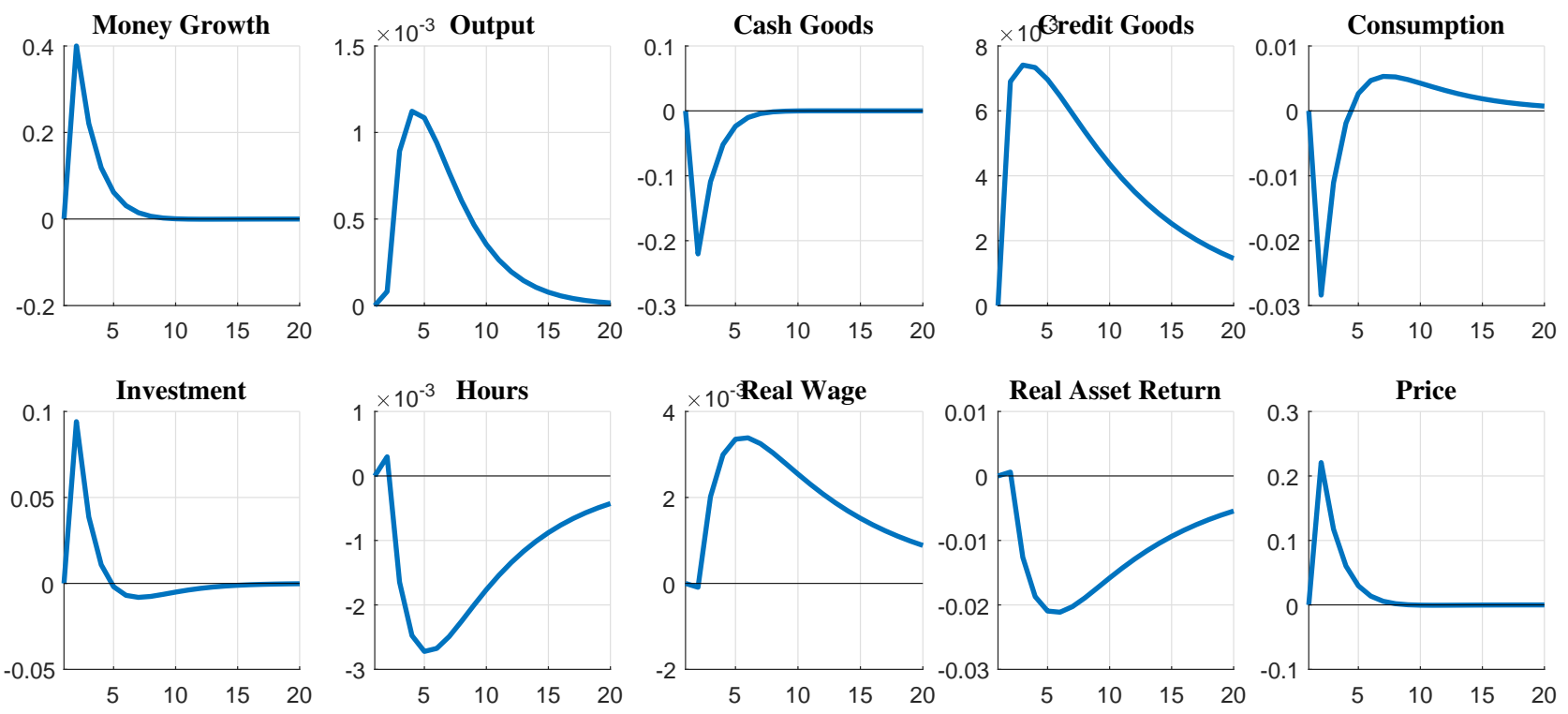

Figure A.1: Impulse-responses of Aggregate Variables: Frictionless Economy

Note: Impulse response to a one-standard-deviation monetary policy (money growth) shock in the model without nominal wage contracts. All variables other than interest rates are logged. The $\mathrm{x}$-axis shows time since the shock in quarters. 


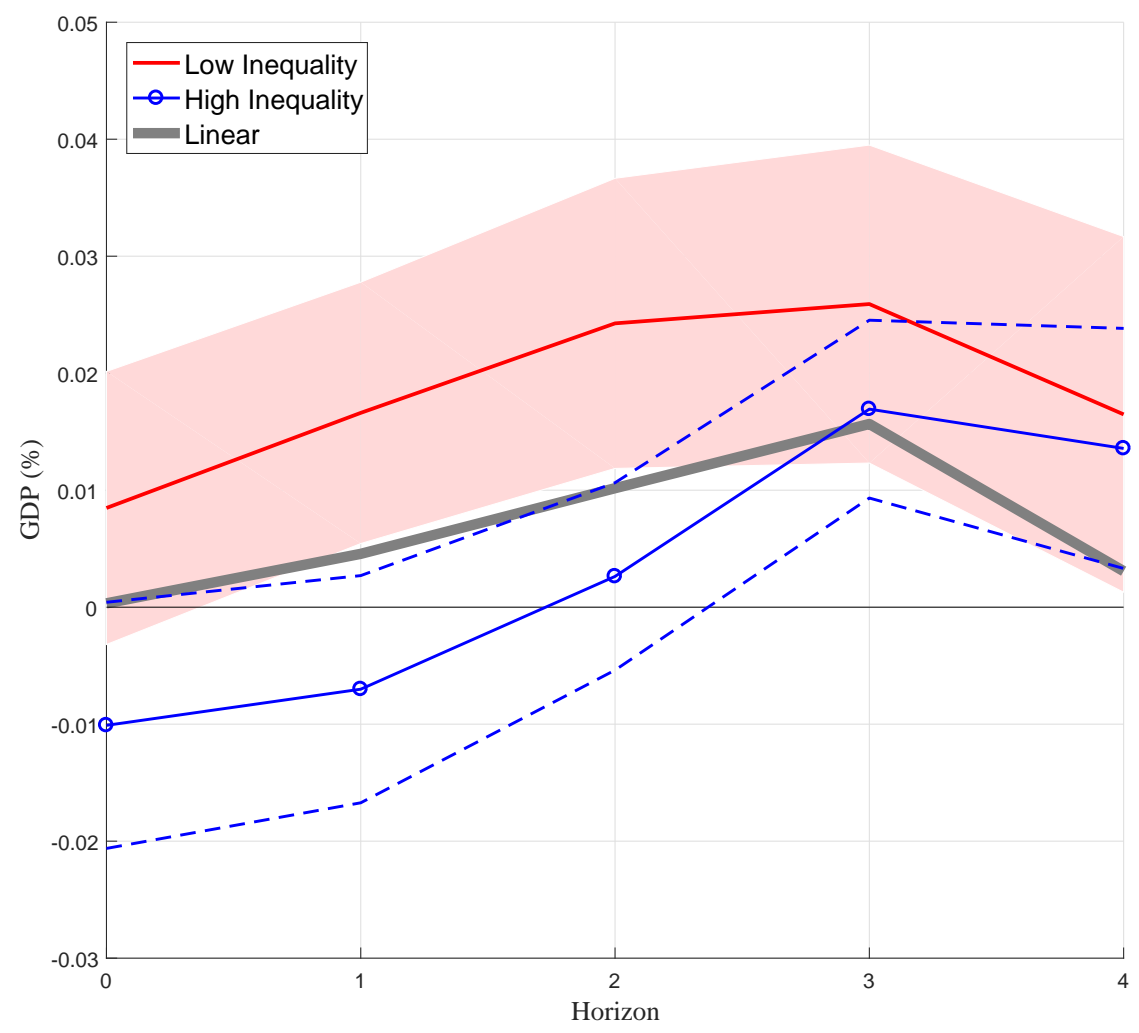

Figure A.2: Inequality and the Effectiveness of Monetary Policy

Note: The red line (the blue line with circles) shows the response of output to an expansionary monetary policy shock for the low (high) inequality states, and the gray thick solid line represents the unconditional response of output in the linear model. Clustered robust standard errors with Newy-West correction are used, and $68 \%$ confidence intervals are shown with shaded area.

Table A.1: Transition Probabilities for Labor Productivity Shock

\begin{tabular}{|c|c|c|c|c|c|c|c|c|c|c|c|c|c|c|c|c|}
\hline & \multicolumn{15}{|c|}{$\mathrm{t}+1$} \\
\hline & & $x_{1}$ & $x_{2}$ & $x_{3}$ & $x_{4}$ & $x_{5}$ & $x_{6}$ & $x_{7}$ & $x_{8}$ & $x_{9}$ & $x_{10}$ & $x_{11}$ & $x_{12}$ & $x_{13}$ & $x_{14}$ & $x_{15}$ \\
\hline \multirow{15}{*}{$\mathrm{t}$} & $x_{1}$ & 0.47 & 0.43 & 0.10 & 0.01 & 0.00 & 0.00 & 0.00 & 0.00 & 0.00 & 0.00 & 0.00 & 0.00 & 0.00 & 0.00 & 0.00 \\
\hline & $x_{2}$ & 0.13 & 0.43 & 0.36 & 0.08 & 0.00 & 0.00 & 0.00 & 0.00 & 0.00 & 0.00 & 0.00 & 0.00 & 0.00 & 0.00 & 0.00 \\
\hline & $x_{3}$ & 0.01 & 0.15 & 0.44 & 0.34 & 0.07 & 0.00 & 0.00 & 0.00 & 0.00 & 0.00 & 0.00 & 0.00 & 0.00 & 0.00 & 0.00 \\
\hline & $x_{4}$ & 0.00 & 0.01 & 0.16 & 0.45 & 0.32 & 0.06 & 0.00 & 0.00 & 0.00 & 0.00 & 0.00 & 0.00 & 0.00 & 0.00 & 0.00 \\
\hline & $x_{5}$ & 0.00 & 0.00 & 0.02 & 0.18 & 0.46 & 0.30 & 0.05 & 0.00 & 0.00 & 0.00 & 0.00 & 0.00 & 0.00 & 0.00 & 0.00 \\
\hline & $x_{6}$ & 0.00 & 0.00 & 0.00 & 0.02 & 0.20 & 0.46 & 0.28 & 0.04 & 0.00 & 0.00 & 0.00 & 0.00 & 0.00 & 0.00 & 0.00 \\
\hline & $x_{7}$ & 0.00 & 0.00 & 0.00 & 0.00 & 0.03 & 0.22 & 0.47 & 0.26 & 0.04 & 0.00 & 0.00 & 0.00 & 0.00 & 0.00 & 0.00 \\
\hline & $x_{8}$ & 0.00 & 0.00 & 0.00 & 0.00 & 0.00 & 0.03 & 0.24 & 0.47 & 0.24 & 0.03 & 0.00 & 0.00 & 0.00 & 0.00 & 0.00 \\
\hline & $x_{9}$ & 0.00 & 0.00 & 0.00 & 0.00 & 0.00 & 0.00 & 0.04 & 0.26 & 0.47 & 0.22 & 0.03 & 0.00 & 0.00 & 0.00 & 0.00 \\
\hline & $x_{10}$ & 0.00 & 0.00 & 0.00 & 0.00 & 0.00 & 0.00 & 0.00 & 0.04 & 0.28 & 0.46 & 0.20 & 0.02 & 0.00 & 0.00 & 0.00 \\
\hline & $x_{11}$ & 0.00 & 0.00 & 0.00 & 0.00 & 0.00 & 0.00 & 0.00 & 0.00 & 0.05 & 0.30 & 0.46 & 0.18 & 0.02 & 0.00 & 0.00 \\
\hline & $x_{12}$ & 0.00 & 0.00 & 0.00 & 0.00 & 0.00 & 0.00 & 0.00 & 0.00 & 0.00 & 0.06 & 0.32 & 0.45 & 0.16 & 0.01 & 0.00 \\
\hline & $x_{13}$ & 0.00 & 0.00 & 0.00 & 0.00 & 0.00 & 0.00 & 0.00 & 0.00 & 0.00 & 0.00 & 0.07 & 0.34 & 0.44 & 0.15 & 0.01 \\
\hline & $x_{14}$ & 0.00 & 0.00 & 0.00 & 0.00 & 0.00 & 0.00 & 0.00 & 0.00 & 0.00 & 0.00 & 0.00 & 0.08 & 0.36 & 0.43 & 0.13 \\
\hline & $x_{15}$ & 0.00 & 0.00 & 0.00 & 0.00 & 0.00 & 0.00 & 0.00 & 0.00 & 0.00 & 0.00 & 0.00 & 0.01 & 0.10 & 0.43 & 0.47 \\
\hline
\end{tabular}

Note: Transition probabilities per quarter. $x_{i}$ denotes a labor productivity grid $i$. Rounding for the table means rows may not sum to 1. 